\title{
Hydrodynamically Guided Hierarchical Self-assembly of Peptide-Protein Bioinks
}

Clara L. Hedegaard, Estelle C. Collin, Carlos Redondo-Gómez, Luong T. H. Nguyen, Kee Woei Ng, Alfonso A. Castrejón-Pita, J. Rafael Castrejón-Pita and Alvaro Mata*

C. L. Hedegaard, Dr. E. C. Collin, C. Redondo-Gómez, Dr. J. R. Castrejón-Pita, Prof. A. Mata School of Engineering \& Materials Science

Queen Mary University of London

London E1 4NS, UK

E-mail: a.mata@qmul.ac.uk

C. L. Hedegaard, Prof. A. Mata

Institute of Bioengineering

Queen Mary University of London

London E1 4NS, UK

E-mail: a.mata@qmul.ac.uk

Dr. L. T. H. Nguyen, Prof. K. W. Ng

School of Materials Science and Engineering,

Nanyang Technological University

Singapore 639798

Prof. A. A. Castrejón-Pita

Department of Engineering Science

University of Oxford

Parks Road

Oxford, OX1 3PJ, UK

Keywords: bioprinting, droplet-on-demand, bioink, self-assembly, peptide amphiphiles 
Effective integration of molecular self-assembly and additive manufacturing would provide a technological leap in bioprinting. This article reports on a biofabrication system based on the hydrodynamically guided co-assembly of peptide amphiphiles (PAs) with naturally occurring biomolecules and proteins to generate hierarchical constructs with tuneable molecular composition and structural control. The system takes advantage of droplet-on-demand (DoD) inkjet printing to exploit interfacial fluid forces and guide molecular self-assembly into aligned or disordered nanofibers, hydrogel structures of different geometries and sizes, surface topographies and higherordered constructs bound by molecular diffusion. PAs were designed to co-assemble during printing in cell diluent conditions with a range of extracellular matrix (ECM) proteins and biomolecules including fibronectin, collagen, keratin, elastin-like proteins (ELPs) and hyaluronic acid. Using combinations of these molecules, NIH-3T3 and adipose derived stem cells were bioprinted within complex structures while exhibiting high cell viability (> $88 \%)$. By integrating self-assembly with 3D-bioprinting, the study introduces a novel biofabrication platform capable of encapsulating and spatially distributing multiple cell types within tuneable pericellular environments. In this way, the work demonstrates the potential of the approach to generate complex bioactive scaffolds for applications such as tissue engineering, in vitro models, and drug screening. 


\section{Introduction}

Tissue engineering (TE) aims to generate complex environments that stimulate the growth of multiple cell types across scales and in a coordinated manner. In this effort, a major goal is the recreation of essential features of the natural extracellular matrix (ECM) that can signal cells selectively and provide specific cell niches. The ECM consists of a mixture of water, fibrous proteins, proteoglycans and glycosaminoglycans, ${ }^{[1]}$ which together make up a rich microenvironment of physical, chemical and biological cues. ${ }^{[2]}$ Structural fibrous proteins such as collagen, elastin, fibronectin and keratin are particularly attractive to create bioactive nanofibrous matrixes with specific molecular signaling, porosity and stiffness. ${ }^{[3]}$

Additive manufacturing (3D printing) has enabled the fabrication of reproducible and structurally complex scaffolds, overcoming a major limiting factor in TE. ${ }^{[4]}$ Within the field of bioprinting (additive manufacturing with living matter), droplet-on-demand (DoD)-based inkjet printing has shown promise owing to its precision, flexibility and compatibility with cells. ${ }^{[5]}$ However, many of the printing inks used in extrusion and inkjet based bioprinting for TE are constrained by stringent printing requirements (e.g. low viscosity, high gel stiffness, fast gelation time and biocompatibility), which significantly limits the choice of materials and the opportunity to build with, or even recreate, key ECM components. ${ }^{[6],[7,8]}$ To overcome this problem, different approaches are being taken to develop bioinks that better support cell culture using decellularised tissue ${ }^{[9]}$ spheroids as building blocks, ${ }^{[10]}$ synthetic materials supplemented with growth factors ${ }^{[4]}$ and hydrogels made from natural proteins and ECM components. ${ }^{[4][11][12]}$ However, whilst these methods have enabled cell encapsulation and growth, they are constrained by the possibility of disease transfer from decellularised tissue, limited cell availability for tissue spheroids and limited structural integrity in the case of natural proteins. Overall, most current bioinks have little control of relevant physical features at the pericellular level such as porosity, stiffness, and nanoscale topography, which are known to play a critical role in exchange of nutrients, ${ }^{[13]}$ cell-cell communication ${ }^{[14]}$ and cell 
growth. ${ }^{[15]}$ In addition, most bioinks lack the capacity to immediately present cells with a tuneable macromolecular matrix that can resemble the native ECM. ${ }^{[4]}$ New bioinks that can incorporate these features would not only improve control of cell behavior and growth within 3D printed structures but also contribute to the development of biofabrication strategies that work with biology in a more cooperative manner. ${ }^{[16]}$

Self-assembling peptides offer a simple biomaterial approach with the potential to recreate both the nanofibrous structure and bioactive elements of the ECM. ${ }^{[17-19]}$ Peptide amphiphiles (PAs), ${ }^{[18]}$ a class of self-assembling peptides, are a versatile platform to create bioactive ${ }^{[20][21]}$ nanofibrous structures, which can be tuned to elicit biological responses. ${ }^{[22]}$ These molecules offer unique opportunities for TE such as a well-defined nanofibrous architecture and presentation of multiple bioactive epitopes with spatial control. PAs can be co-assembled with biopolymers such as heparin $^{[23]}$ and hyaluronan ${ }^{[24]}$ in order to improve bioactivity and structural complexity. Furthermore, we have recently demonstrated the possibility to co-assemble PAs with elastin-like proteins, ${ }^{[25]}$ enabling the fabrication of a hierarchical material with enhanced functionality and opening the possibility to co-assemble with other ECM components. In this way, it may be possible to use PAs to co-assemble and organize proteins into rich peptide-protein composites that can recreate the structural complexity of the ECM.

We report a new approach to biofabrication that integrates molecular co-assembly with bioprinting. The system takes advantage of interfacial forces generated between solutions of co-assembling molecules during DoD printing, to guide self-assembly across scales into complex micro/macroscopic geometries with aligned or randomly oriented protein/peptide nanofibers. We show that co-assembling PAs, with a variety of fibrous proteins and biomolecules, generates a biocompatible ink that can be used to print multiple cell types with high viability and spatial control within complex hierarchical structures. 


\section{Results}

\subsection{Integrating self-assembly of multiple molecules with 3D bioprinting.}

Bioprinting aims to build complex tissue-like structures with controlled molecular diversity and microscale resolution. However, the choice of materials that are able to recreate the natural $\mathrm{ECM}^{[11]}$ or selectively guide cell behavior ${ }^{[12]}$ is limited due to the rheological properties required for printing. ${ }^{[6]}$ On the other hand, molecular self-assembly aims to reproducibly organize functional building-blocks into well-defined nanostructures but tends to lack reproducibility and order beyond the nanoscale. We propose a new material fabrication platform that integrates the benefits of bioprinting and molecular self-assembly to overcome current major limitations of these two fields. Our approach relies on the co-assembly of PAs with proteins or biomolecules whilst exploiting the droplet-on-demand (DoD) printing process to control and guide self-assembly across length scales into complex TE scaffolds. As a result, our strategy enables bioprinting of molecularly complex environments with structural hierarchy, biomolecules that can recreate the natural ECM to guide cell behaviors immediately after printing and the possibility to integrate and selectively localize multiple cell types. The key advantages of the system are summarized in Figure 1, ranging from molecular control at the nanoscale to macroscale structural control. The control elements can be categorized as either part of the versatile bioink or the advanced fabrication process. Combined, we have a molecularly designed and hierarchical biofabrication method. 


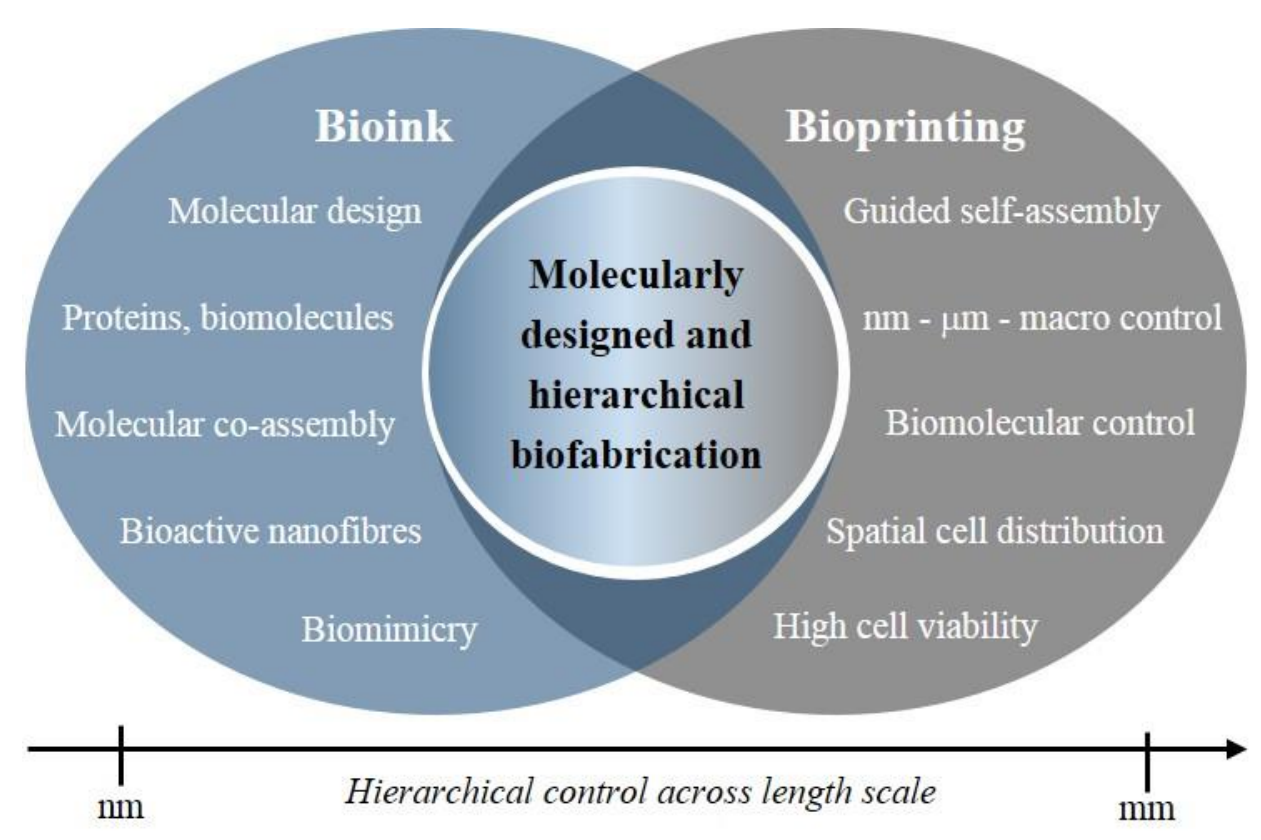

Figure 1. Overview of parameters directing the structure and formation of hydrogels in the developed system.

\subsection{Components of the co-assembling bioink.}

We have previously demonstrated the capacity to co-assemble ELPs with oppositely charged PAs. ${ }^{[25]}$ Here, a major design element of our bioink is the use of PAs to co-assemble with and organize oppositely charged fibrous proteins or biomolecules into hierarchical structures. In this way, the bioink permits the use of multiple macromolecules and enables immediate cell encapsulation within a tuneable ECM-like matrix. PA molecules consist of a charged hydrophilic head, a $\beta$-sheet forming domain and a hydrophobic alkyl tail $\left(\mathrm{C}_{16}\right)$ enabling their self-assembly into functional nanofibers $^{[26,27]}$ (Figure 2a). In this study two main PAs were used to characterize the co-assembling system (Table $1, \mathrm{PA}_{1} \& \mathrm{PA}_{2}$ ). First, $\mathrm{PA}_{1}$ is based on a previously reported sequence for PA/biomolecule co-assembly ${ }^{[24,25]}$ (Table 1, $\mathrm{PA}_{3}$ ), but modified to include the biological epitope VPGIG taken from natural elastin ${ }^{[28]}$ in order to explore the potential to include further bioactivity through the PA molecule. Furthermore, the positively charged head group (KKK) confers solubility, promotes electrostatic interaction and triggers co-assembly with negatively charged ECM biomolecules. On the other hand, $\mathrm{PA}_{2}$ is also based on $\mathrm{PA}_{3}$ but designed to have a reduced overall Page 6 
charge (HHK) similar to that of $\mathrm{PA}_{1}$ and without additional bioactivity (Table 1). Both $\mathrm{PA}_{1}$ and $\mathrm{PA}_{2}$ were designed to have a positive charge as most ECM macromolecules are negatively charged. The positively charged $\mathrm{PA}_{4}$ has been previously used as a cell culture material ${ }^{[29]}$ and was used as a control for interaction with positively charged macromolecules (Table 1). The second component of the bioink is a macromolecule that can be either a protein or an ECM biomolecule. We first used the protein keratin as it can easily be obtained, comprises cell adhesion sequences ${ }^{[30]}$ and has previously been used to aid drug ${ }^{[31]}$ and growth factors delivery. ${ }^{[32]}$ The intermediate filaments in keratin are linked by disulphide bonds, making the fibers strong and durable. ${ }^{[32]}$ As a result, keratin gels have previously been shown to have favorable mechanical and biomedical properties ${ }^{[33]}$ and to be a viable ink for 3D printing. ${ }^{[34]}$ The keratin used here contained some basic domains but predominantly type I (acidic) filaments (Figure S1), resulting in a negative zeta potential (Table 1). Therefore, given the presence of both acidic and basic domains in keratin, both negative and positive PAs were used as part of the co-assembling bioink.

\begin{tabular}{|c|c|c|c|c|c|c|c|}
\hline Group & Component & $\begin{array}{l}\mathbf{M W}^{+} \\
(\mathbf{k D a})\end{array}$ & $\begin{array}{c}\text { Conc. } \\
\left.(\mathbf{m m o l ~ d m})^{-3}\right)\end{array}$ & $\begin{array}{l}\text { Viscosity } \\
\text { (mPa s) }\end{array}$ & $\begin{array}{l}\text { Surface tension } \\
\qquad\left(\mathrm{mN} \mathrm{m}^{-1}\right)\end{array}$ & $\begin{array}{l}\text { Zeta potential } \\
\quad(\mathrm{mV})\end{array}$ & $\mathbf{P i}^{+}$ \\
\hline $\mathrm{PA}_{1}$ & $\mathrm{C}_{15} \mathrm{H}_{31} \mathrm{CONH}-\mathrm{V}_{3} \mathrm{~A}_{3}$ VPGIGK $-\mathrm{CONH}_{2}$ & 1.57 & 6.4 & $6.8 \pm 0.6$ & $74.7 \pm 1.0$ & $29.1 \pm 2.8$ & 14.0 \\
\hline $\mathrm{PA}_{2}$ & $\mathrm{C}_{15} \mathrm{H}_{31} \mathrm{CONH}-\mathrm{V}_{3} \mathrm{~A}_{3} \mathrm{H}_{2} \mathrm{~K}-\mathrm{CONH}_{2}$ & 1.17 & 8.5 & $2.4 \pm 0.6$ & $72.7 \pm 4.1$ & $29.3 \pm 0.5$ & 9.1 \\
\hline $\mathrm{PA}_{3}$ & $\mathrm{C}_{15} \mathrm{H}_{31} \mathrm{CONH}-\mathrm{V}_{3} \mathrm{~A}_{3} \mathrm{~K}_{3}-\mathrm{CONH}_{2}$ & 1.15 & 8.7 & $5.1 \pm 1.1$ & $74.7 \pm 1.3$ & $67.5 \pm 3.3$ & 10.3 \\
\hline $\mathrm{PA}_{4}^{*}$ & $\mathrm{C}_{15} \mathrm{H}_{31} \mathrm{CONH}-\mathrm{V}_{3} \mathrm{~A}_{3} \mathrm{E}_{3}-\mathrm{CONH}_{2}$ & 1.15 & 8.7 & - & $80.0 \pm 0.2$ & $-19.2 \pm 0.4$ & 3.4 \\
\hline Protein & Keratin (Human hair) & $40-50$ & 0.2 & $3.4 \pm 0.3$ & $65.2 \pm 0.2$ & $-31.4 \pm 4.3$ & 4.5 \\
\hline
\end{tabular}

Table 1. Key material parameters. Overview of PAs and the protein keratin used in this study along with their key properties; molecular weight (MW), concentration (Conc.), viscosity (at room temperature), surface tension (at room temperature), zeta potential and isoelectric point (Pi). The notation $\left(^{*}\right)$ denotes heat treated PA solution. (Measured values are reported as an average with standard deviation $( \pm)$, with samples $\geq 2$ for all conditions). 

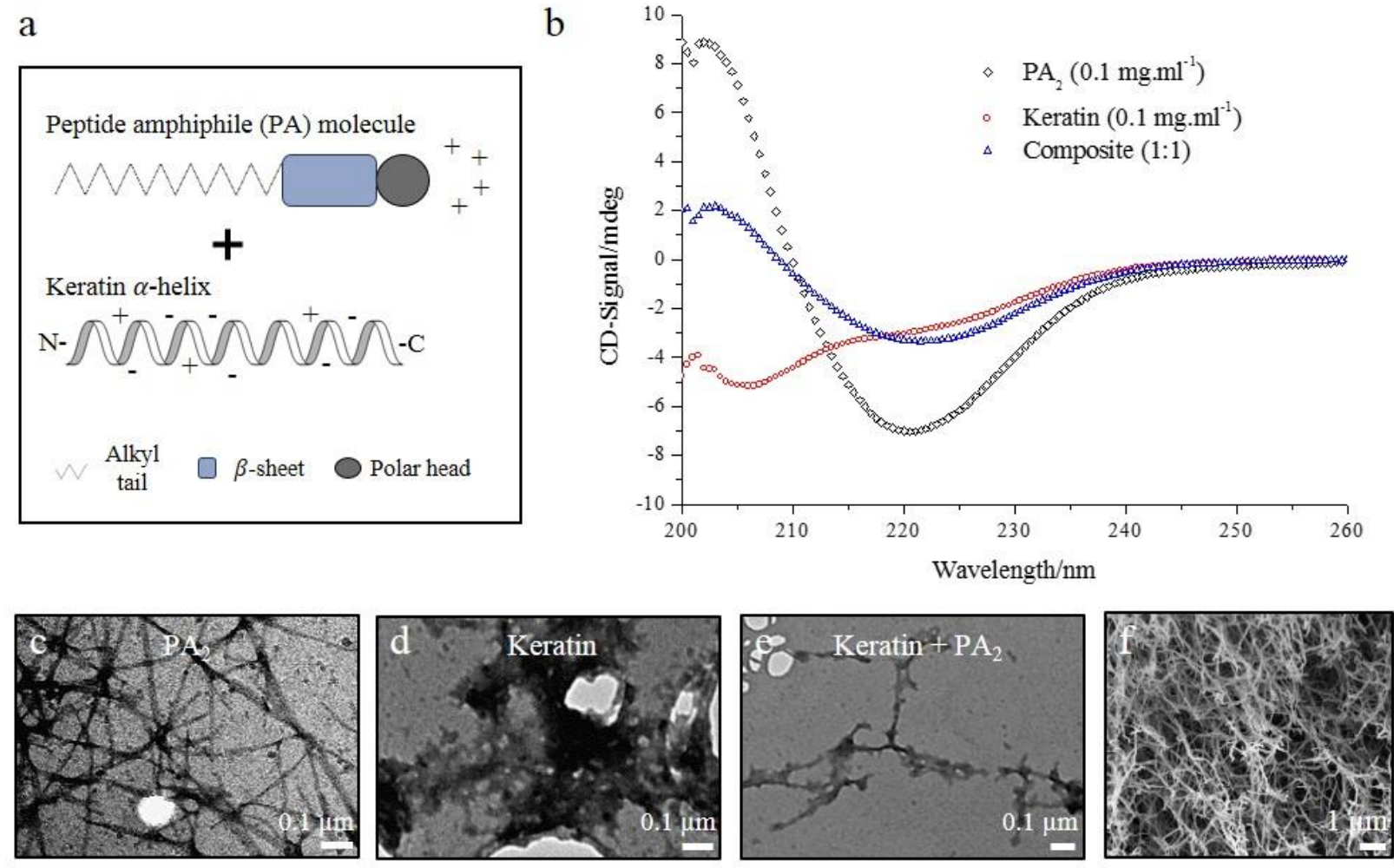

Figure 2. Characterization of the interaction between PA and keratin. (a) Schematic of a $\mathrm{PA}_{2}$ molecule and an $\alpha$-helix keratin molecule, (b) CD Spectra to visualize the secondary protein structure of $\mathrm{PA}_{2}(\beta$-sheet) and keratin ( $\alpha$-helix), as well as post interaction (Composite 1:1 (v/v)), (c, d, e) TEM of pure $\mathrm{PA}_{2}$ (nanofibers), pure keratin (flaky objects) and the $\mathrm{PA}_{2} /$ keratin mixture (thick fibers) and (f) SEM of the fibrous network inside the $\mathrm{PA}_{2} /$ keratin gel.

\subsection{Evaluation of the PA/keratin gel as a potential bioink.}

We first evaluated the interaction and fabrication of PA/keratin hydrogels using the PAs described in Table 1. PA/keratin interactions were investigated using circular dichroism (CD) and transmission electron microscopy (TEM). As expected, both PAs $\left(\mathrm{PA}_{1} \& \mathrm{PA}_{2}\right)$ exhibited a $\beta$-sheet signal $^{[20]}$ whilst keratin predominantly showed an $\alpha$-helix conformation ${ }^{[35]}$ (Figure 2b, $\mathrm{PA}_{2}$ ) (Figure $\mathrm{S} 3 \mathrm{PA}_{1} \& \mathrm{PA}_{2}$, molar based). The $\mathrm{PA}_{2} /$ keratin mixture exhibited a considerably different $\mathrm{CD}$-signal compared to $\mathrm{PA}_{2}$ on its own, indicating that conformational changes take place in the presence of Page 8 
each other. The negative absorption, centered around $220 \mathrm{~nm}$, decreased in intensity compared to the pure $\mathrm{PA}_{2}$ signal. Additionally, the negative absorption around $205 \mathrm{~nm}$ in pure keratin was not present in the mixture. TEM was used to confirm the interaction between the two bioink components. $\mathrm{PA}_{2}$ exhibited the expected micrometer length high aspect ratio fibers ${ }^{[20]}$ (diameter 15 $\pm 7 \mathrm{~nm}$ ) (Figure 2c), whilst keratin exhibited sub micrometer flake-like structures (Figure 2d). In contrast, the TEM micrographs of $\mathrm{PA}_{2}$ in presence of keratin revealed thicker fibers (diameter $34 \pm$ $11 \mathrm{~nm}$ ) compared to $\mathrm{PA}_{2}$ and with a rugged appearance (Figure 2e), suggesting their interaction.

The co-assembled hydrogels were first made prior to using the print-head by injecting a droplet of PA $(5 \mu \mathrm{l})$, using a fine tip pipette, into a droplet of keratin $(20 \mu \mathrm{l})$ or vice versa. Both components were dissolved in cell diluent to enable cell suspension prior to assembly. After injection a gel is assembled within milliseconds (ms) but co-assembly between keratin and PA molecules continue for longer periods of time, as diffusion between the two solutions takes place. To account for this effect, gels were left in solution for $24 \mathrm{~h}$ before further studies were conducted. The keratin was observed to diffuse towards the PA, meaning that in the case of PA injected into keratin, the outer solution would diffuse towards the PA drop (Figure S4, S5). Scanning electron microscopy (SEM) revealed a nanofibrous gel structure (Figure 2f). The porosity arises from the network of nanofibers, which mimics the architecture of the microenvironment found in vivo. ${ }^{[14]}$ An advantage of coassembling systems is the possibility to tune both the chemical and mechanical properties of the hydrogel by simply changing the mixture ratio. Compression tests were carried out at $20 \%$ strain, to obtain the peak and equilibrium moduli of hydrogels made with ranging keratin concentration. The peak moduli for 10 and $20 \mathrm{mg} \mathrm{ml}^{-1}$ keratin concentration were found to be $0.5 \pm 0.3 \mathrm{kPa}$ and $0.9 \pm 0.3 \mathrm{kPa}$, respectively. The equilibrium moduli were found to be $\sim 20 \%$ of the peak modulus (Figure S6), which is soft in comparison to commonly used bioinks such as for example agarose 2 $\%(w / v)$ gels (equilibrium modulus $15 \mathrm{kPa}) .{ }^{[36]}$ However, varying the concentration of keratin can potentially be used to control the stiffness. Furthermore, it has previously been shown that Page 9 
modifying the PA sequence can change the gel stiffness. ${ }^{[20]}$ In this way, our system opens for the opportunity to adjust the structural properties of the hydrogel without compromising the droplet jetting or modifying the critical rheological properties of the ink during printing. In other words, the stiffness of the resulting hydrogel can be tuned independently of the rheological properties of the jetted drop. However, it is important to mention that while soft hydrogels can enhance cell viability during bioprinting, ${ }^{[37]}$ this will depend on the specific cellular requirements.

Hydrogels were stable in cell culture media, maintaining their structure and weight following two weeks incubation at $37{ }^{\circ} \mathrm{C}$ (Figure S7). The porosity and high water content of hydrogels facilitate the transfer of nutrients and waste ${ }^{[38]}$. The gels were found to contain $>90 \%$ water as measured by comparing the weight of the hydrated samples with that of after freeze drying (Figure S8). Altogether, the material's peptide/protein composition, rapid self-assembly and stability in cellfriendly conditions, nanofibrous architecture, mechanical properties, molecular tunability and highly hydrated nature represent attractive advantages for its usage in biofabrication.

\subsection{The co-assembling bioprinting set-up.}

In this work we use an acoustic-driven print-head working under the DoD mode (Figure 3a). The system can easily incorporate a dual-liquid configuration, either by printing into a liquid pool or by using multiple nozzles printing consecutively. ${ }^{[39]}$ DoD printing is able to achieve higher resolution than extrusion methods and offers no direct contact with the substrate. ${ }^{[5]}$ In brief, the print-head consists of a cylindrical liquid reservoir (diameter $10 \mathrm{~mm}$, height $3 \mathrm{~mm}$ ), the actuator (8 Ohms and $0.1 \mathrm{~W}, 20 \mathrm{~mm}$ diameter loudspeaker) and a nozzle plate. In this system, the nozzle diameter can range from $100 \mu \mathrm{m}$ to $0.5 \mathrm{~mm}$. The actuator simply pushes the liquid through the nozzle to create a droplet. The diameter of the nozzle and the characteristics of the driving signal, pulse width and amplitude determine the size and speed of droplets. The driving signal in these experiments 
corresponds to a single pulse and was produced by a pulse generator. Only driving signals that produced single droplets were chosen in these experiments. The system benefits from its simplicity, as speed and droplet size can easily be modified. Given the droplet size, gravitational effects are not important during drop formation (Bond number $<0.05)$. The bulk solution was either in a well $(50$ $\mu \mathrm{l} /$ well) or in soft PDMS reservoir pools $(5 \mathrm{~mm} \times 10 \mathrm{~mm}$ x $1 \mathrm{~mm}, 50 \mu \mathrm{l})$ (Figure 3a). One component of the co-assembly system (PA/protein) was used as the ink (jetted solution) while the other as the receiving substrate (hereafter referred to as 'bulk solution') (Figure 3b).
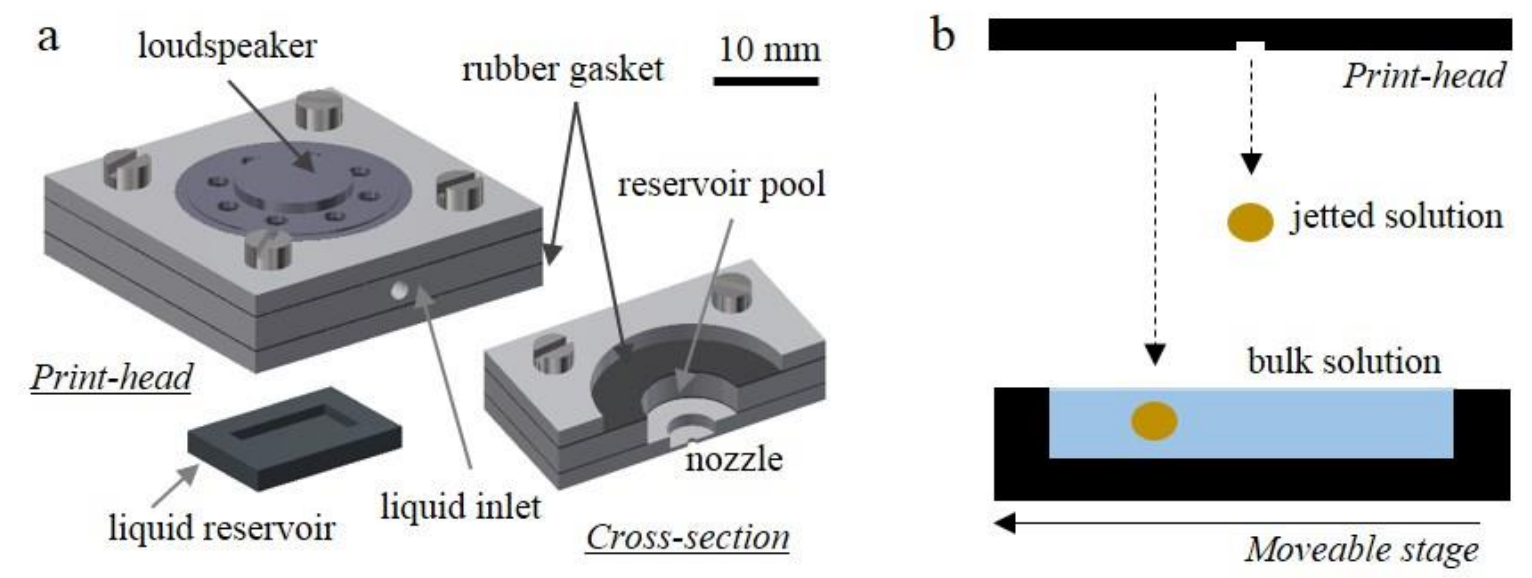

Figure 3. Printing set-up. Schematics of (a) the print-head specifications and (b) the experimental set-up.

\subsection{The co-assembling bioprinting advantages}

Using either PA or keratin as the jetted solution and a nozzle diameter of $500 \mu \mathrm{m}$, we fabricated reproducible micro gels with a diameter of $\sim 700 \mu \mathrm{m}$ for keratin into PA (Figure 4a) and of $\sim 800$ $\mu \mathrm{m}$ for PA into keratin (Figure 4c). The size of the drop and subsequently the gel can easily be adjusted by the DoD system without having to change the nozzle diameter. For instance, when using a $500 \mu \mathrm{m}$ nozzle diameter and varying jetting characteristics such as pulse duration and amplitude, it is possible to fabricate hydrogels ranging from $800-1800 \mu \mathrm{m}$ in size (Figure 4d). 
Whilst this study was done primarily with a $500 \mu \mathrm{m}$ diameter nozzle, we have shown that it is possible to create hydrogels with diameters as small as $168 \pm 15 \mu \mathrm{m}$ in size when using a $100 \mu \mathrm{m}$ diameter nozzle (Figure S9). As a result, macroscopic structures could be built with gels of different diameter without having to change the nozzle.

The printed gels exhibit a similar fibrous network as those formed by pipetting. However, modulation of the printing process enables the reproducible generation of controlled shear forces formed at the interface between the jetted and bulk solutions, which can be used to guide the selfassembly process with spatial control. This is an opportunity to further improve tuneability and structural complexity of the bioinks at multiple scales and on demand. The final gel shape was achieved by modulating the conditions and concentrations of the jetted and bulk solutions. Adjustment of these parameters permitted the formation of co-assembled gels with different geometries such as biconcave (keratin jetted into PA) (Figure 4a, b) and toroidal (PA jetted into keratin) shapes (Figure 4c). The dynamics of droplets impacting at a liquid-liquid interface is known to be ruled by liquid properties and force of impact. ${ }^{[40]}$ For example, the forces associated with the impact of the droplet, causes the printed gels to exhibit a larger diameter compared to the original droplet. In our experiments, the toroidal gels were on average $\sim 1.6$ times bigger than the initial droplet (Figure 4d). Whilst the formation of gel shapes using droplet dynamics has been reported, ${ }^{[41-43]}$ our approach demonstrates the interplay between the kinetics of self-assembly and that of fluid mechanics (Figure 4e). In addition, the molecular co-assembly process is short and within the fast-occurring timescales of drop (inkjet) dynamics $(<5 \mathrm{~ms})$, allowing unprecedented control of the nano and microstructure. Furthermore, this strategy opens the possibility to use shear forces to guide molecular self-assembly of multiple types of molecules across length scales. For example, in the case of the toroidal gels, shear forces can be used to not only guide PA/keratin coassembly into its ring shape but also channel-like micro topographies on the surface of the inner part of the ring (Figure 4f, 4g, 4h). Moreover, the shear forces can also be used to guide self- 
assembly within the bulk of the material. For example, in the case of the toroidal gels, the nanofibers acquire a spiral layering shape within the gel (Figure 4i). Both surface and bulk geometrical features are formed by the shear forces generated by the fluid moving around the deforming droplet during impact (Figure 4e), taking place over ms. These results reveal the possibility of using the printing-controlled fluid dynamics to spatially guide the self-assembly of
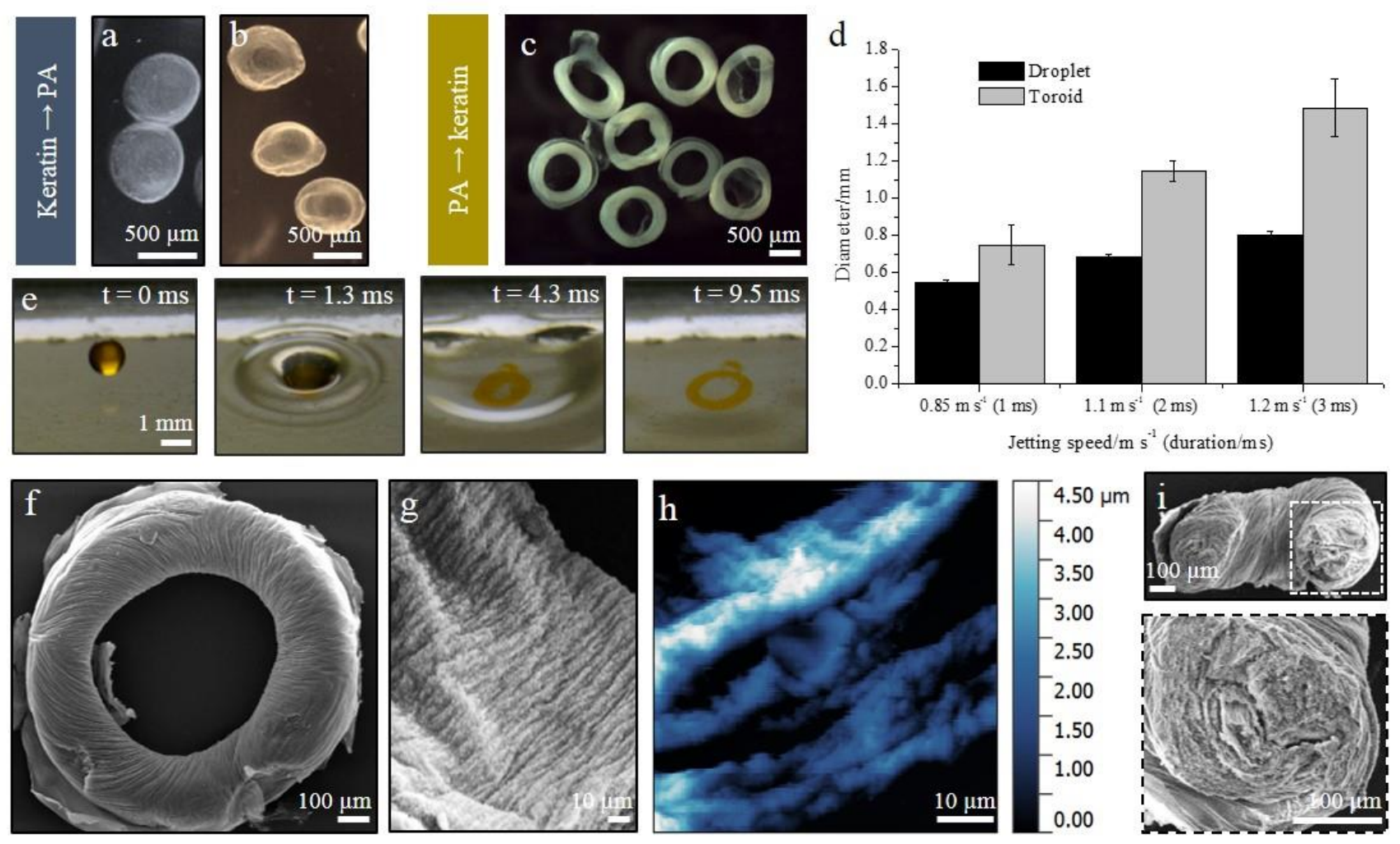

molecular building-blocks across multiple length scales.

Figure 4. Method of gel fabrication and characterization. Examples of (a) biconcave gels made with keratin $\left(20 \mathrm{mg} \mathrm{ml}^{-1}\right)$ and (b) keratin $\left(10 \mathrm{mg} \mathrm{ml}^{-1}\right)$ jetted into $\mathrm{PA}_{1}\left(10 \mathrm{mg} \mathrm{ml}^{-1}\right)$, (c) Examples of toroidal gels made with $\mathrm{PA}_{1}\left(10 \mathrm{mg} \mathrm{ml}^{-1}\right)$ jetted into keratin $\left(10 \mathrm{mg} \mathrm{ml}^{-1}\right)$, (d) Comparison between droplet and toroid size, (e) Image sequence from a video of formation. $\mathrm{PA}_{3} 1 \%$ into keratin $2 \%$ (Pulse: $20 \mathrm{~V} 1 \mathrm{~ms}$ ). Video taken at $9100 \mathrm{fps}$, (f) SEM image of one toroidal gel $(500 \mu \mathrm{m})$ and $(\mathbf{g})$ zooming in on the surface architecture of a toroidal gel, (h) the surface topography assessed with AFM, (i) A cross-section of a $\mathrm{PA}_{1} /$ Keratin hydrogel and an enlargement of the right hand crosssection. 


\subsection{Theoretical aspect of co-assembling bioprinting.}

Our approach provides the opportunity to bioprint combining advantages of both molecular coassembly and fluid dynamics. Therefore, it is crucial to understand and characterize the printing coassembly process. As a droplet impacts a liquid interface, it undergoes deformation as it moves through the stationary liquid pool. ${ }^{[44]}$ The surface tension of the droplet is overcome by inertia at the interface between the two liquids, forcing the droplet to radially spread outwards from the point of impact as it is immersed. The edges of the droplet subsequently start to curl upwards and inwards, generating a hollow center. The process sees the droplet transform from tear shaped, to a red-bloodcell like shape and finally to a toroidal shape. ${ }^{[41,42]}$ By controlling the fluid properties and gelation speed, the process can be stopped intermediately to obtain transitional shapes. The dynamics of droplets impacting a pool of the same liquid are known to be dependent on two dimensionless groups that encompass the relevant liquid properties, the size of the droplet and the impacting

speed. ${ }^{[4,46]}$ In contrast, the dynamics of droplets onto a pool of a different liquid are known to also depend on the ratio of the liquids viscosities. ${ }^{[42]}$ In this work, we demonstrate that two dimensionless groups can be used to determine and control the final shape of self-assembled structures.

The parameters affecting the dynamics of the droplet pre and post immersion can be written as a function of the Weber (We) number and the Reynolds (Re) number. ${ }^{[42,43,46]}$ The Re number represents the ratio between inertial and viscosity forces while the We number quantifies the ratio between inertia and surface tension effects. In our study, the third dimensionless group, $\mu_{R}$, is introduced to take into account the ratio of viscosities between the droplet and the liquid pool. 
(1)

(2)

$$
\mathrm{We}_{\mathrm{d}}=\rho v^{2} D / \sigma
$$

$$
\operatorname{Re}_{\mathrm{d}}=\rho \nu D / \mu
$$

$$
\mu_{\mathrm{R}}=\mu_{\mathrm{d}} / \mu_{\mathrm{b}}
$$

where $\rho$ is density, $D$ is the droplet diameter, $\mu$ the viscosity, $\sigma$ the surface tension and $v$ is the droplet impacting velocity (Figure S11). Subscript $d$ denotes droplet and subscript $b$ denotes bulk solution. To link these groups with the resulting structures, We was plotted against the viscosity ratio of the droplet/bulk solution for all observed cases (Figure 5).

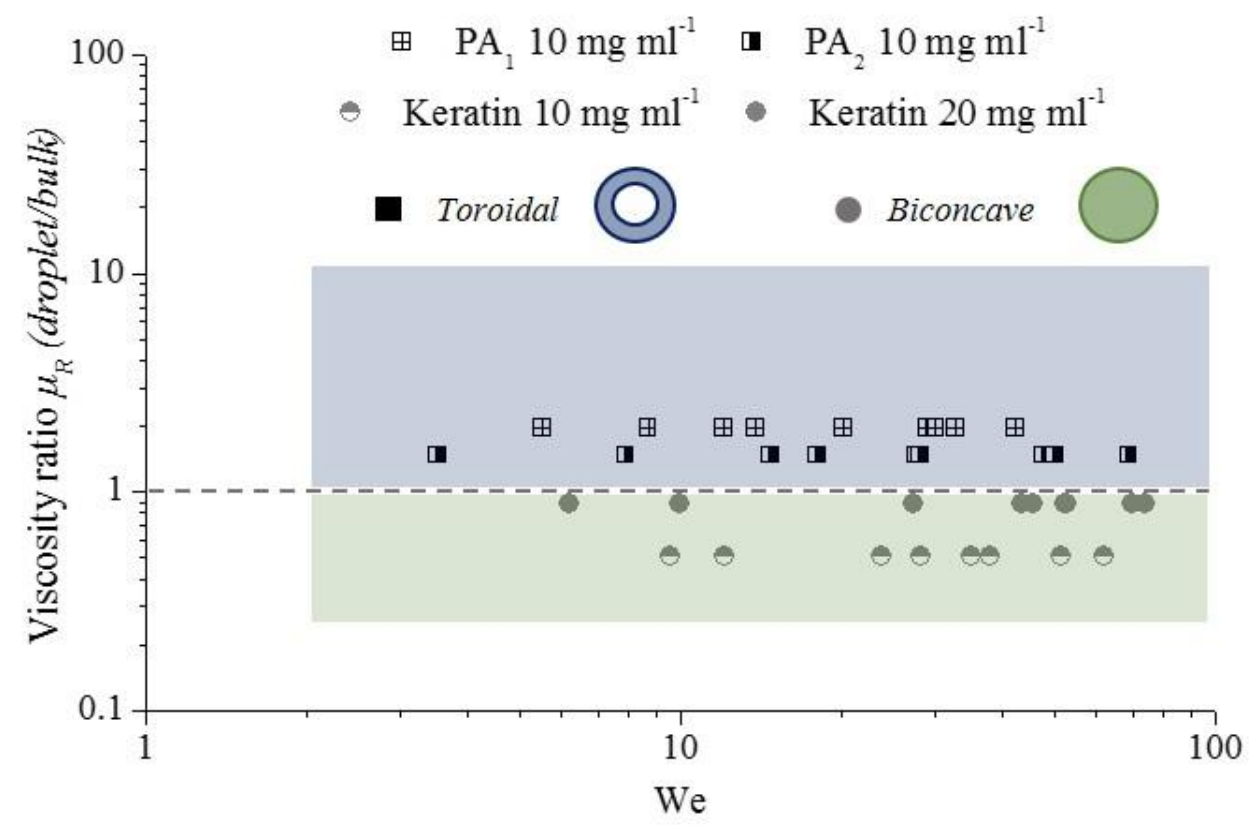

Figure 5. Operating region with fitted experimental results. The viscosity ratio of droplet/bulk solution $\left(\mu_{R}\right)$ plotted against the dimensionless Weber number $(\mathrm{We})$. 
The experimental data points for $\mathrm{PA}_{1} / \mathrm{PA}_{2}$ and keratin (nozzle $500 \mu \mathrm{m}$ ) are plotted in Figure 5 and reveal an operating region of $3<\mathrm{We}<80$ and $70<\mathrm{Re}<600$ (Droplet velocity $0.5-2.5 \mathrm{~m} \mathrm{~s}^{-1}$ ). On the horizontal axis, the region is limited by the maximum jetting speed $(v)$ at very low We and a minimum droplet diameter $(D)$ at high We. When decreasing the nozzle size to $100 \mu \mathrm{m}$ in diameter, the lower operating range limit is shifted to include $15<\mathrm{Re}$ and $0.5<\mathrm{We}$. The operating range permits us to predict the behavior of other liquids or at other scales. At low Re, e.g. high viscosities or small diameters, the pressure pulse produced by the speaker does not provide sufficient power to eject a droplet, yielding a minimum droplet velocity. At the other end of the spectrum, at high Re and low We, surface tension effects lead to the formation of undesired satellite droplets (small droplets ejected with the main droplet) removing the droplet ejection control. These jetting limits can, to a certain extent, accommodate various jetting parameters. For example, a higher viscosity liquid requires either a higher jetting speed or a larger nozzle. On the contrary, if smaller sizes $(D)$ are required, the liquid should have a lower viscosity or a slower jetting speed. In these experiments, our operating range includes nozzle sizes ranging from $100 \mu \mathrm{m}$ to $0.5 \mathrm{~mm}$ in diameter and liquid viscosities ranging from 1 to $10 \mathrm{cP}$.

All PA solutions were found to have viscosities $<10 \mathrm{cP}$, limiting the operating region on the droplet/pool viscosity ratio. At $\mu_{R}>1$ toroidal gels were observed, while biconcave gels can be produced at viscosity ratios of $\mu_{R}<1$ (Figure 5). The biological relevance of the toroidal gel is of great interest, as it has a higher surface area/volume ratio and shorter diffusion paths compared to traditional spherical or square structures. ${ }^{[41]}$ In other words, when encapsulating cells in this geometry they experience a more homogenous exchange of nutrients with the surrounding media, minimizing the chances for cell death in the center of the gel. In the $\mu_{R}<1$ region, the bulk solution has a comparatively higher viscosity than the jetted one, which reduces the deformation dynamics, leading to the gelation of a biconcave shaped gel. In this case the balance of forces between the bulk 
solution and the droplet are such that there is insufficient time and energy to deform the droplet prior to gelation taking place.

\subsection{Versatility of the approach}

In TE applications, the target tissue determines the structural and chemical properties of the scaffold. In biofabrication, an ideal bioink system would behave as a versatile toolkit capable of providing specific molecular and structural components on the basis of the particular application. The possibility to use PAs to co-assemble with and organize multiple types of proteins and biomolecules represents an attractive bioink opportunity to build micro-to-macro structures using molecular building blocks of the ECM. To demonstrate this possibility, we followed a similar process as that used with keratin to co-assemble PA with both collagen and collagen/fibronectin (Figure 6c, 6d). Collagen was chosen as it is one of the most predominant proteins in the ECM and its combination with fibronectin validates the system's potential to co-assemble with a range of ECM proteins with tuneable and specific composition.

We have previously demonstrated the possibility to modify co-assembled structures through slight modifications of the molecular structure of the two components. ${ }^{[25]}$ In one example we demonstrated that when $\mathrm{PA}_{3}$ is combined with an ELP, a co-assembled membrane is formed, which can be controllably opened upon contact with a surface within the first minute of formation. ${ }^{[25]}$ Using this system, $\mathrm{PA}_{3}$ was jetted into ELP and, as expected, resulted in a closed membrane formed at the liquid-liquid interface between the two solutions, which subsequently opened at the liquid/air interface (Figure 6b). In this system, the propensity for the membrane to open upon contact with an interface seems to disturb the formation of the toroidal shape. However, when using a PA-HA system known to assemble into sacs ${ }^{[24]}$ and by jetting a high MW HA into a solution of $\mathrm{PA}_{3}$, a similar closed membrane is generated but acquiring a hollow toroidal structure (Figure 6a). In this case the droplet deformation leading to a toroidal gel takes place in spite of the difference in co- 
assembly mechanism. These results reveal that the morphology of the gel at the microscale can be tuned independently of the self-assembly process and further demonstrate the versatility of our approach.

A higher level of structural and hierarchical control would emerge from the capacity to align the PA/macromolecule nanofibers whilst controlling their hierarchical assembly into complex shapes. To test this possibility, we created similar PA/macromolecule hydrogels but using a previously reported negatively-charged PA, which upon thermal treatment is able to assemble into aligned PA fibers $^{[29]}$ (Table 1, $\mathrm{PA}_{4}$ ). We hypothesize that the thermally treated PA can co-assemble with different proteins while preserving its tendency for alignment, generating a PA/protein gel of aligned co-assembled fibers. To explore this hypothesis, we first confirmed that the negatively charged $\mathrm{PA}_{4}$ can co-assemble with keratin, confirming that both overall negative and positive PAs can interact with this protein. Subsequently, heated $\mathrm{PA}_{4}$ was jetted into keratin, forming the toroidal gels but now exhibiting aligned nanofibers as validated by birefringence imaging (Figure 6e) and SEM (Figure 6f). Using the same $\mathrm{PA}_{4}$ but without the thermal treatment generated similar toroidal gels but with randomly aligned nanofibers. Interestingly, whilst the interfacial forces significantly modified the microstructure of the self-assembling gel, they did not disturb the aligned assembly of the nanofibers. In contrast, the interfacial forces direct the assembly of the nanofibers predominantly in the circular axial direction. We subsequently tested the alignment process using $\mathrm{PA}_{2}$, which yielded comparable birefringence patterns in the toroidal gel shape, and suggests that the thermal alignment treatment may be applied to other PA molecules. Overall, these results reveal the potential to create 3D PA/macromolecule gels with high nano/micro structural control, expanding further the material's potential to precisely engineer cell niches and guide cell behavior. Furthermore, by combining bioprinting with self-assembly in this manner, the system takes advantage of the co-assembly process to generate structural complexity beyond the microscale without relying on the printing resolution but rather on a guided bottom-up co-assembly process. 
Spatially controlled molecular self-assembly in a single drop is an attractive advantage. Individual hydrogels can exhibit molecular diversity and well-defined nano-micro structural elements, which could be used to control cell behavior within a single printed drop. In this way, single drops could be used to recreate chemical (i.e. proteins, peptides) and physical (i.e aligned or disordered nanofibers) features of specific tissues and used for example as complex in vitro models. However, the use of this material as a bioink for larger biofabricated structures would require a simple way to bind individual gels into higher order structures. To this end, we hypothesize that the diffusiondependent co-assembly process could be used to bind adjacent printed gels together, as molecules from the inside of the drops diffuse towards the bulk solution and onto adjacent drops. To test this possibility, the print-head was connected to a mechanical stage to allow combined control of droplet interval and stage movement, facilitating precise positioning of the jetted drops (Figure S13). Automated control was achieved using a simple custom written Arduino code. Both the use of molecular diffusion as a binding mechanism and the print-head as an additive manufacturing tool were demonstrated by creating structures of connected biconcave (Figure 6g) gels as a result of jetting keratin into $\mathrm{PA}_{1}$. To confirm that the binding of adjacent gels resulted from the diffusion of keratin, we repeated the experiment but jetting $\mathrm{PA}_{1}$ into a solution of keratin, placing each toroid adjacent but not overlapping. In this case, gels did not bind to each other (Figure 6h), which supports the hypothesis that diffused keratin from the inside of a jetted drop can assemble with the PA-rich surface of closely adjacent drops. Taking advantage of this opportunity, and using a smaller nozzle diameter $(200 \mu \mathrm{m})$, we created more complex structures including for example stars (Figure 6i) or sheets (Figure 6j) from toroidal gels using $\mathrm{PA}_{2}$ into keratin. In both cases a higher droplet interval was used (1.4 seconds) to allow partial gel overlap as seen in Figure 6 k-1. These results support the possibility to use the co-assembling system as a versatile bioink for biofabricating complex scaffolds such as bioactive patches for wound healing or soft tissue repair. 

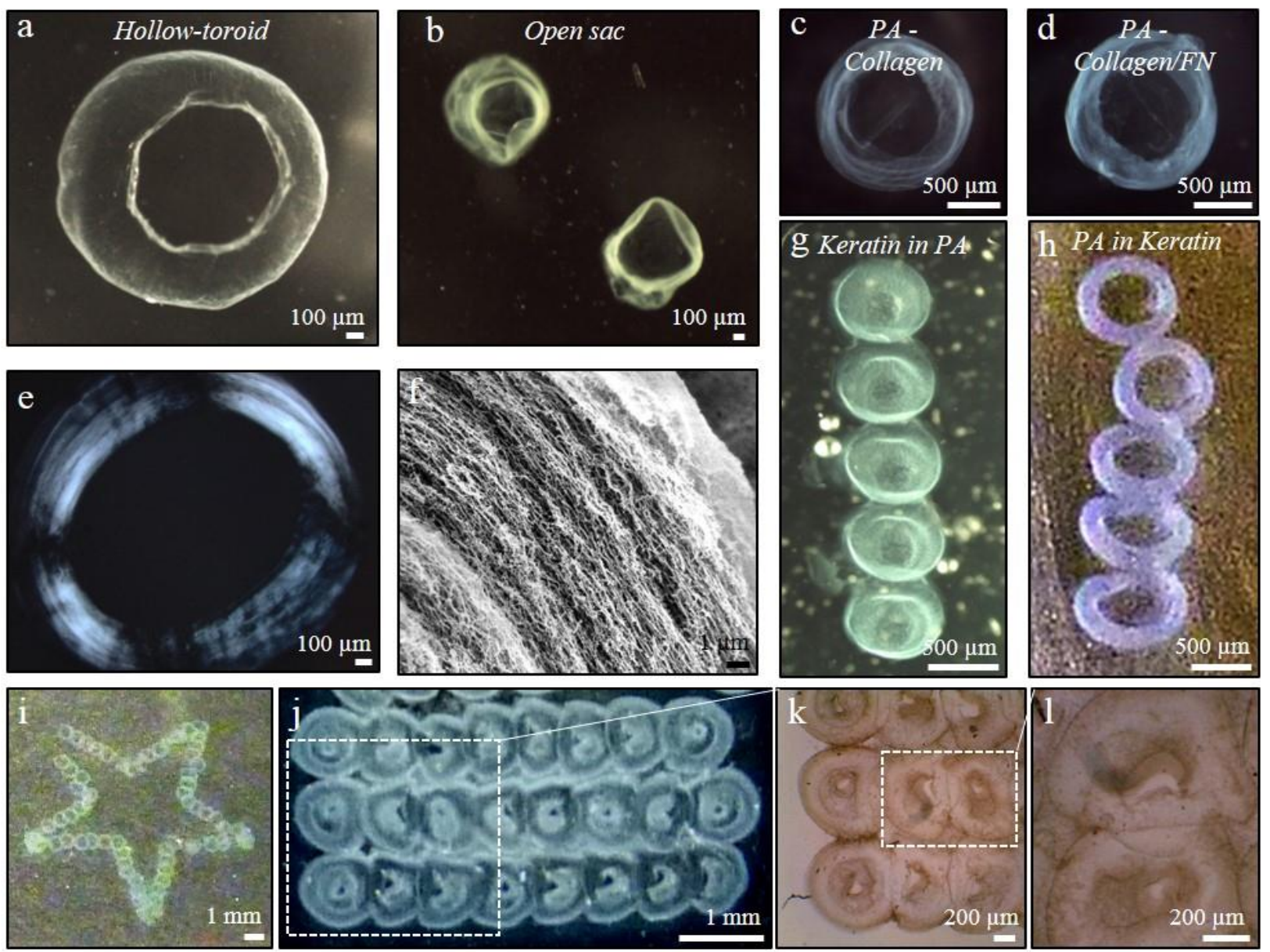

Figure 6. Printing control and versatility. (a) Hollow toroidal gels, formed from high-MW HA and $\mathrm{PA}_{3}$, (b) open sacs made from $\mathrm{PA}_{4}$ with ELP, $(\mathbf{c}, \mathbf{d})$ Heated $\mathrm{PA}_{4}$ co-assembled with Collagen and Collagen/FN, (e) Birefringent toroidal gel formed from heated PA 4 /Keratin, (f) SEM of the aligned nanofibers in a birefringent $\mathrm{PA}_{2} /$ keratin gel, (g) Assembling lines (500 $\mu \mathrm{m}$ diameter nozzle) of connected biconcave gels and (h) lines of toroidal gels, and more complex structures using a 200 $\mu \mathrm{m}$ diameter nozzle, (i) a star shape formation of toroidal gels and (j) a sheet of toroidal gels with $(\mathbf{k}, \mathbf{l})$ close ups of the gel structure.

\subsection{Suitability for cell culture.}

The incorporation of cells within the co-assembling printing process was assessed to further demonstrate the possibility to be used as a bioactive bioink for biofabrication. An established, non- 
specific, cell lineage (NIH-3T3) was chosen for the study to demonstrate the suitability of the process as a whole rather than for a specific target tissue. Cells encapsulated in a bioink undergo significant stresses during the printing process including pre-printing physical mixing, constrained nozzle and/or force applied during printing and post-processing steps. ${ }^{[47]}$ The method of droplet generation used here is relatively gentle, as the cells are only briefly exposed to the shear stress of the nozzle during the short duration of the driving pulse. ${ }^{[5]}$ Moreover, there are no physical forces exerted on the ink mixed with cells, as otherwise experienced in for example extrusion or contact printing. ${ }^{[6,8]}$ To assess the effect of the printing process on cell viability, we conducted a live/dead assay on a HEPES solution mixed with cells jetted into an empty well plate at a range of jetting speeds and pulse durations. High cell viability was observed (average $88 \pm 8 \%$ ) (Figure 7a), even under strenuous conditions of increasing jetting speeds and pulse duration. The observed cell viability for printing lies in the high-end of inkjet printing, which is one of the most gentle bioprinting methods. ${ }^{[8]}$ This is an important result because it demonstrates that the shear forces generated during the process to guide self-assembly and provide nano/micro structure to the printed gels do not affect cell viability.

The ease and versatility of the system enables the incorporation of cells with spatial control. For example, when printing toroidal-shaped gels jetting a $\mathrm{PA}_{2}$ drop into a keratin solution and using a high cell density $(5 \mathrm{M}$ cells $/ \mathrm{ml})$, cells included in the $\mathrm{PA}_{2}$ solution were embedded inside the gel. In this case, an average cell viability of $97 \pm 8 \%$ was obtained (Figure S14) and the toroidal structure formed despite the high cell density (Figure 7c). On the other hand, when cells were included in the bulk keratin solution prior to jetting the $\mathrm{PA}_{2}$ drop, they adhered and grew on the outside of the selfassembled toroidal gel (Figure 7b). In this case, cell viability was $97 \pm 3 \%$ (Figure S14) and again did not affect the formation of the toroidal-shaped gel (Figure 7d). The cell experiment was repeated following the same protocol but printing primary Adipose Derived Stem Cells (ADSCs). In this case, we observed a similar low effect of the printing process on ADSC viability (93\% of 
the control) (Figure S15), further demonstrating the biocompatibility of the process with a more biologically-relevant cell type. These results confirm that our approach, in addition to providing control over molecular diversity and hierarchical structures, enables high cell viability. The printing process benefits from a short application of force, attributing to the high viability. Additionally, the co-assembly-based bioink is based on low viscosity liquids, which further reduces shear stresses induced on suspended cells. Moreover, the results show that the co-assembly between PA and protein does not affect cell viability. The ability to co-culture multiple cell types is of particular importance in TE. We show here that the developed process can easily be used for co-culture applications by encapsulating cells in both the jetted and the bulk solution. In this case, the resulting toroidal gel incorporates one population of cells inside originating from the jetted solution (magenta) and another on the outside surface of the gel (green) as a result of the cells suspended in the bulk solution prior to printing (Figure 7e). The fabrication system is suited for soft tissue constructs such as for example skin models, drug testing, or soft tissue repair. The ability to create reproducible microenvironments, with a versatile molecular ink composition, makes the technique well suited for soft tissue constructs including for example skin or cancer in vitro models, drug screening platforms, or bioactive patches for regenerative medicine or drug or cell delivery. However, as the study introduces a new approach to bioprinting, the experiments were chosen to demonstrate the versatility of the system, the opportunities with respect to its capacity to control both molecular and structural features in a hierarchical manner, and its potential for diverse applications. 

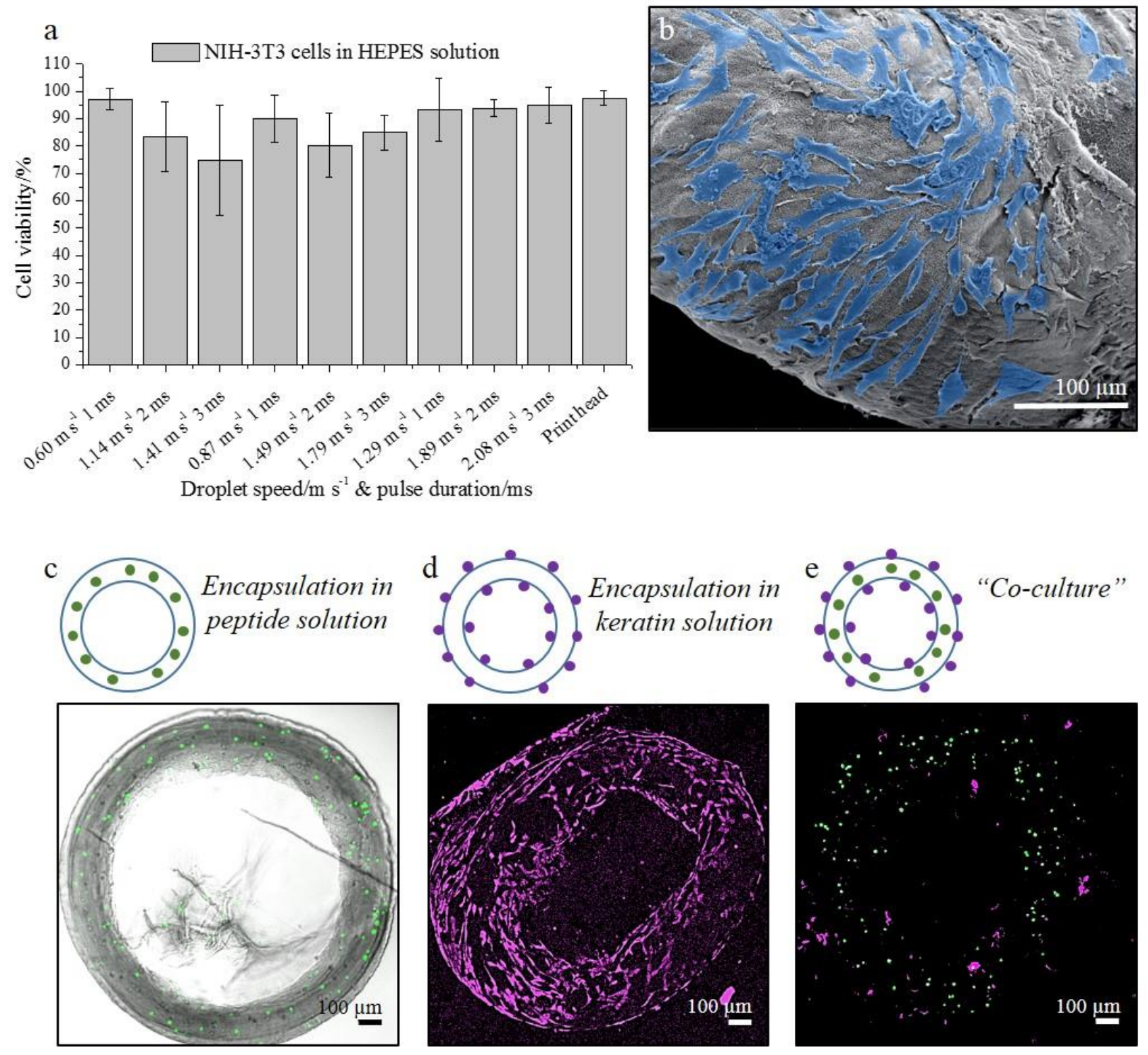

Figure 7. Cell viability and comparison between structures. (a) Viability of cells encapsulated in HEPES jetted at increasing amplitude and pulse duration, (b) SEM of a toroidal gel with cells adhering to the outside (cells were suspended in the keratin solution) (c) Visualization of cell encapsulation in toroidal gels, where cells are suspended in the $\mathrm{PA}_{2}$ solution (d) in the keratin solution

and (e) in both, hence a co-culture. Cells in the PA solution are stained green and in the keratin solution magenta. 


\section{Conclusion}

Our results have shown the possibility of using the PA/macromolecule co-assembly system as a tuneable nanofibrous bioink for DoD-based printing. By modulating printing conditions and the coassembly components, we can alter important gel features with a high level of control including size and shape, surface topography and the organization of the nanofibrous network (Figure 4 and 6). We have also shown the system's potential and versatility by co-assembling PAs with a variety of proteins, building higher order structures with the printed micro gels and demonstrating its suitability for building complex scenarios such as co-cultures with spatially controlled cells (Figure 7). By integrating printing with peptide/macromolecule co-assembly, our approach enables the possibility to build, with an unprecedented level of precision, from the molecular to the macroscale using a bioink that can be molecularly designed to mimic key components of the ECM.

The capacity to print gels using PAs to co-assemble with and organize macromolecules validates the possibility to create tuneable bioinks capable of incorporating ECM proteins and relevant biomolecules as both structural and signaling components. Keratin, whilst overall negatively charged, is able to co-assemble with both positively charged and negatively charged PAs. We hypothesize that the co-assembly is driven by either acidic or basic domains of the keratin filaments, depending on the charge of the PA used. As we have previously shown using ELPs, ${ }^{[25]}$ it is likely that hydrophobic interactions also play an important role in the co-assembly. However, the specific mechanisms dictating the PA/keratin interaction are beyond the scope of this study. In addition, co-assemblies can be generated using different PA molecules (Figure 4 and 6) and the PA sequence can be easily modified to modulate the properties of the generated co-assembled structure. ${ }^{[25][20]}$ Furthermore, gel stiffness can potentially be adjusted by modifying the bioink properties . The ability to tune gel stiffness is an important advantage for the use of the system as a bioink. The stiffness of the ECM is a critical component to guide cell behavior. ${ }^{[48]}$ It is also well- 
recognized that bioink stiffness plays a crucial role in the viability and behavior of cells before, during and after bioprinting. ${ }^{[6]}$

Previous studies have investigated the notion of using self-assembling materials as inks for bioprinting. Their suitability for a range of applications such as self-assembling polymers for inkjet printing $^{[49]}$ and peptide-based hydrogels for micro extrusion ${ }^{[37,50]}$ has been demonstrated. These studies are based on self-assembling peptides that can gel over dry surfaces, maintaining their shape and being able to encapsulate cells. Our study provides a number of advantages over these systems.

First, our bioink is able to incorporate multiple macromolecules, not only enabling the presentation of different proteins, but also incorporating them as structural components, recreating the way these molecules are presented in in vivo. We have shown that a range of proteins and biomolecules and combinations of them can be used in the co-assembly system (Figure 6a-d). Essentially, the coassembly ink can be viewed as a toolbox of materials from which one can choose ECM components based on the requirements of the target tissue. This flexibility also overcomes a limitation otherwise faced by bioprinting, namely, that print-heads are custom designed per material. This multi molecular toolbox can be used to fabricate micro environments with a wide range of relevant molecular compositions, without requiring a new print-head design. Second, our approach takes advantage of interfacial fluid forces to direct self-assembly hierarchically. At one level, printing parameters can be tuned so that upon jetting, fluid forces can spatially direct the assembly process, generating gels of specific sizes while acquiring different reproducible shapes (Figure 4a-c). At another level, the fluid-fluid interplay between the jetted and stagnant solution can also be used to modify the gel surface to introduce surface micro topographies (Figure $4 \mathrm{f}-\mathrm{h}$ ). In addition, interfacial forces also permit assembly of aligned PA/protein nanofibers in specific microscale organization (i.e. toroidal shape) (Figure 6e-f), demonstrating further the distinctive hierarchical tuneability of the system. Third, our approach takes advantage of the diffusion-dependent mechanism of gelation to bind printed gels into higher-order structures. As proof of concept we generated linear bound 
structures (Figure 6g-h) and sheets of toroidal gels (Figure 6j-1). The ability to print 3D macrostructures with well-defined nano-to-micro domains enhances significantly the potential bioactivity of the bioink as structural features such as aligned nanofibers ${ }^{[51]}$, surface topographies ${ }^{[15]}$ and microstructures are known to affect cell behaviors. Finally, the cell-friendly co-assembly process enables the introduction and localization of at least two cell-types, providing an opportunity to biofabricate complex structures with multiple types of cells localized in specific regions. We demonstrated this possibility by generating toroidal gels with cells outside and cells inside (Figure 7e). Keeping the above in mind, the biofabricated individual gels or structures would lend themselves well to soft tissue studies as well as high-throughput screening platforms to recreate specific environments such as tumor or inflammation sites due to the molecular and physical versatility enabled by the system.

Whilst interest in 3D-printing for TE continues to grow, the availability of suitable bioinks has been limited. ${ }^{[8]}$ Here, we propose a new method to biofabricate hierarchical and molecularly designed structures based on hydrodynamically guiding the co-assembly of peptides with proteins and biomolecules across multiple size scales. This approach integrates a novel bioink that enables molecular diversity, the nanoscale precision of self-assembly, and the use of whole proteins and bioactive peptides within a process that facilitates structural hierarchy, micro-to-macro precision, bioprinting and the spatial distribution of multiple cells. In this way, the system provides solutions to important limitations in both self-assembly (such as micro- and macro-scale precision) and bioprinting (such as molecular diversity, nanoscale control and biomimicry). Furthermore, the study opens new opportunities in biofabrication by enabling for the first time the possibility to control biomolecular and physical elements of the pericellular environment at the molecular, nano and microscale. This capability opens the possibility to biofabricate in a more cooperative manner with biology. $^{[16]}$ 


\section{Methods}

Peptide amphiphiles: $\mathrm{PA}_{2}\left(\mathrm{C}_{15} \mathrm{H}_{31} \mathrm{CONH}-\mathrm{V}_{3} \mathrm{~A}_{3} \mathrm{H}_{2} \mathrm{~K}\right)$ and $\mathrm{PA}_{3} \quad\left(\mathrm{C}_{15} \mathrm{H}_{31} \mathrm{CONH}-\mathrm{V}_{3} \mathrm{~A}_{3} \mathrm{~K}_{3}\right)$ were purchased from Biomatik (Canada) $(98.55 \%$ and $98.10 \%$ purity respectively) and subsequently treated with $\mathrm{HCl}$ to remove residual TFA. $\mathrm{PA}_{1}\left(\mathrm{C}_{15} \mathrm{H}_{31} \mathrm{CONH}-\mathrm{V}_{3} \mathrm{~A}_{3} \mathrm{VPGIGK}_{3}\right)$ and $\mathrm{PA}_{4}$ $\left(\mathrm{C}_{15} \mathrm{H}_{31} \mathrm{CONH}-\mathrm{V}_{3} \mathrm{~A}_{3} \mathrm{E}_{3}\right)(92 \%$ and $95 \%$ purity respectively) were synthesized in-house using solidphase peptide synthesis (SPPS) employing standard 9-fluorenylmethoxycarbonyl (Fmoc) protection chemistry on an automated peptide synthesizer (CS Bio, USA) at 1 mmol scale on a 4methylbenzhydrylamine (MBHA) Rink Amide resin (Novabiochem Corporation, USA) to yield a free amide at the C-terminus in each PA. Additional notes on purity and method can be found in Supplementary information (Figure S2.1-4).

Hair keratin: A heterogeneous mixture of hair keratins were extracted from random hair samples obtained from hair salons, by modifying a previously established protocol. ${ }^{[30]}$ Briefly, washed hair was decontaminated in $95 \%$ ethanol and delipidized with a mixture of chloroform and methanol $(2: 1 \mathrm{v} / \mathrm{v})$ for $24 \mathrm{~h}$ at room temperature. Extraction was then done in reducing conditions of $0.125 \mathrm{M}$ $\mathrm{Na}_{2} \mathrm{~S} .9 \mathrm{H}_{2} \mathrm{O}$ at $\mathrm{pH} 10-13.5,40{ }^{\circ} \mathrm{C}$, for $4 \mathrm{~h}$. The resulting mixture was exhaustively dialyzed against deionized water, using cellulose dialysis tubing of 10,000 Da MWCO, and subsequently freezedried and stored at $-20{ }^{\circ} \mathrm{C}$ until use. Earlier characterization had showed that the material obtained with this approach consisted of predominantly intact hair keratins. ${ }^{[7,52]}$

Reagents: All chemicals, unless otherwise stated, were purchased from Sigma-Aldrich. Bovine Collagen Type I (3.1 mg ml $\mathrm{m}^{-1}$ ) was purchased from Advanced BioMatrix (US). Fibronectin was 
purchased from R\&D Systems (USA). HA (High MW) was purchased from LifeCore Biomedical (USA). ELP (EI2 RGD2) was purchased from TP Nanobiotechnology (Spain).

Hydrogel preparation: PA and biomolecules were dissolved in HEPES buffer (10 mM HEPES + $0.9 \% \mathrm{NaCl}, \mathrm{pH} 7.5)$ at concentrations $5-50 \mathrm{mg} \mathrm{ml}^{-1}$. PA $(5 \mu \mathrm{l})$ was injected into protein solution (20 $\mu$ 1). For compression tests larger gels were made (20:100 $\mu 1$ PA in protein). The hydrogels were left for $24 \mathrm{~h}$ at room temperature before conducting further analysis.

Print-head and experimental set-up: The print-head as described in main text, was connected with a mechanical stage, controlled using a GRBL protocol and 4 stepper motors $\left(1.8^{\circ} / \mathrm{Step}\right)$. The printhead nozzle plate, was fixed at a height of $35 \mathrm{~mm}$ above the surface unless otherwise stated. A drop repetition of down to one per 1.5 seconds was used. A $100 \mathrm{~W}$ LED light, optical diffuser and a high-speed camera (Phantom V170) were used for the visualization. Droplet velocities and diameter were obtained using image-analysis. The liquid height of the bulk solution (the pool) was kept constant at approximately $1 \mathrm{~mm}$.

Zeta-potentials: The zeta-potentials were measured at $25^{\circ} \mathrm{C}$ on a Zetasizer (Nano-ZS ZEN 3600, Malvern Instruments, UK). Materials were dissolved in HEPES buffer $\left(0.1 \mathrm{mg} \mathrm{ml}^{-1}\right)$ and $\mathrm{pH}$ adjusted to $\mathrm{pH} 7.5$. Measurements were repeated at least twice $(\mathrm{n} \geq 2)$.

Circular dichroism $(C D)$ : $\mathrm{CD}$ was used to characterize the secondary structure of the PA solution $\left(\mathrm{PA}_{1}\right.$ and $\left.\mathrm{PA}_{2}\right)\left(0.1 \mathrm{mg} \mathrm{ml}^{-1}\right)$, protein solution $\left(0.1 \mathrm{mg} \mathrm{ml}^{-1}\right)$ and mixture $(1: 1 \mathrm{v} / \mathrm{v} \mathrm{PA}$ and protein), all made using HEPES buffer. Experiments were repeated at equal molar concentration $(20 \mu \mathrm{M})$ 
(Figure S3). Measurements were carried out at $25^{\circ} \mathrm{C}$ using a $0.1 \mathrm{~cm}$ path length and $300 \mu \mathrm{l}$ volume cuvette (Chirascan, Applied Photophysics, UK). ( $\mathrm{n} \geq 3)$

Transmission Electron Microscopy (TEM): Samples were dissolved in HEPES buffer at a final concentration of $1 \mathrm{mM}$. Samples were mounted on copper TEM carbon copper grid (Agar Scientific, Stansted, UK). The grids were immerged in the samples solutions for five minutes. Excess was removed using filter paper before incubation with $2 \%$ filtered uranyl acetate solution for 30 seconds. Grids were then washed with ultrapure water for $30 \mathrm{~s}$ and air dried for $24 \mathrm{~h}$ at room temperature. Bright-field TEM imaging was performed on a JEOL 1230 Transmission Electron Microscope operated at an acceleration voltage of $80 \mathrm{kV}$. All the images were recorded by a Morada CCD camera (Image Systems). At least ten images were taken per sample for further analysis.

Scanning Electron Microscopy (SEM): Samples were fixed using $2.5 \%$ glutaraldehyde (GTA) in water for a minimum of $3 \mathrm{~h}$ at room temperature. The crosslinked samples were then dehydrated by immersion in increasingly concentrated ethanol solution $(25,50,70,80,90,95,100 \%)$, for 5 min twice in each solution. The dehydrated samples were dried using a critical point dryer (CPD) (K850, Quorum Technologies, UK) and gold coated before imaging on an Inspect F50 (FEI Comp, The Netherlands). ( $\mathrm{n} \geq 5$ )

Mechanical properties: $20 \mu 1 \mathrm{PA}_{2} /$ keratin gels, made with varying keratin concentration (10-20 mg $\mathrm{ml}^{-1}$ ), were used for the compression tests (Instron 5967 Tensile \& Compression tester). The tests were carried out in culture media to simulate the environment experienced by the cells. A preload of $0.0005 \mathrm{~N}$ was used to contact the sample and determine the gauge length. The samples were compressed to $20 \%$ strain at $10 \%$ per s and then held for $120 \mathrm{~s}$. Videos of the compression test Page 29 
were used to obtain the gel area. The gel shape was approximated to a sphere. $2 \%(\mathrm{w} / \mathrm{v})$ agarose sphere gels were used for comparison. $(\mathrm{n} \geq 5)$

Atom-force-microscopy (AFM): AFM (NT-MDT Ntegra) was used to map the surface topography of toroid-shaped gels. The gels were formed using the printing set-up ( $\mathrm{PA}_{1}$ and keratin). After $24 \mathrm{~h}$, the gels were cross linked using GTA $2.5 \%$ and subsequently mounted onto metal disks immediately prior to the measurement. AFM probes $(325 \mathrm{kHz}, 40 \mathrm{~N} / \mathrm{m})$ were purchased from $\mu$ masch (UK). All experiments were carried out in air with hydrated samples $(n=2)$.

Surface tension: The surface tension was measured using a bubble pressure tensiometer. The measurements were carried out at $23^{\circ} \mathrm{C}$ and at surface age $100 \mathrm{~ms} .(\mathrm{n}=2)$.

Viscosity: High speed-videos were analyzed using a Matlab image analysis protocol to obtain droplet diameter, speed and droplet oscillations (Figure S10). In-flight droplet oscillations were used to obtain viscosity and surface tension, using the Rayleigh oscillating method ${ }^{[53]}$ (Figure S12).

Printing viability: Droplets of HEPES/cell solution (5M cells/ml) were printed into empty wells (96 well plate). $200 \mu \mathrm{l}$ of DMEM supplemented with $10 \% \mathrm{FBS}$ and $1 \% \mathrm{P} / \mathrm{S}$ was added to each well after printing. Additionally, $10 \mu \mathrm{l}$ samples from the print-head were taken for the control and suspended in supplemented DMEM. Cell viability was assed immediately using a Live/Dead assay kit (Thermo Fisher Scientific, UK) of green-fluorescent calcein-AM (4 mM) and red-fluorescent ethidium homodimer-1 (2 mM). The reagents were diluted 1:1000 in supplemented DMEM, and 25 $\mu l$ of the prepared solution was added to each well, followed by imaging. ( $\mathrm{n} \geq 4$ for all conditions) 
Cell encapsulation NIH-3T3 \& Adipose Derived Stem Cells (ADSCs): NIH-3T3 (Sigma Aldrich, UK) and ADSCs were cultured in supplemented DMEM. Confluent (80\%) cells were suspended in HEPES buffer prior to mixing with the $\mathrm{PA}_{2} / \mathrm{HEPES}$ or the keratin/HEPES solution. $\mathrm{PA}_{2}$ and keratin were prepared at $20 \mathrm{mg} \mathrm{ml}^{-1}$ in HEPES solution and subsequently diluted to $10 \mathrm{mg} \mathrm{ml}^{-1}$ with the solution of cells suspended in HEPES. A final cell concentration of 5,000,000 cells ml ${ }^{-1}$ was used. A $1 \mathrm{~mL}$ syringe with a blunt needle was used to load the print-head. Droplets of $\mathrm{PA}_{2} /$ cell solution were jetted directly into wells containing $50 \mu \mathrm{l}$ of keratin solution (10-20 mg ml $\mathrm{m}^{-1}$ ) (96 well plate). 30 min after gel formation $200 \mu 1$ of supplemented DMEM was added to each well. The control samples, taken from the print-head and the PA/cell solution, were suspended in $200 \mu 1$ of supplemented DMEM. Cell viability was assessed 48h after encapsulation using Live/Dead assay as described earlier ( $\mathrm{n} \geq 10$ for NIH-3T3 studies and $\mathrm{n}=3$ for ADSCs studies).

Co-culture study: Two types of cell tracker dye were used, CM-Dil (red) and CMFDA (green), purchased from Invitrogen (UK) to visualize cell location post encapsulation in keratin and $\mathrm{PA}_{2}$. The dyes were dissolved in supplemented DMEM (final concentration of $1 \mathrm{mg} \mathrm{ml}^{-1}$ ). Cells were suspended in $5 \mathrm{~mL}$ of the dye/DMEM mixture, and kept under agitation for $30 \mathrm{~min}$. Subsequently the cells were washed 3 times with fresh supplemented DMEM before proceeding with cell encapsulation as described previously. Cells were visualized using a laser confocal microscope (LSCM, Olympus FluoView 1000, Japan) with excitation wavelengths $488 \mathrm{~nm}$ and 543/594 nm (n $=5)$.

Statistical analysis: Numerical data were expressed as mean \pm standard deviation (SD). All experiments were repeated at least three times. Analysis was performed using GraphPad Prism 15 (La Jolla, USA). One-way analysis of variance (ANOVA) for multiple comparisons were 
employed. Non parametric statistics were used when the samples did not present a normal distribution (Mann-Whitney test). Statistical significance was accepted when $\mathrm{p}<0.05$.

\section{Supporting Information}

Supporting Information is available from the Wiley Online Library or from the author.

\section{Acknowledgments}

We thank everyone in the MATA Group and the technical workshop at Queen Mary University of London for technical advice and results discussions. Thank you to Elena Tomas Bort (BSc Student) for providing the $100 \mu \mathrm{m}$ nozzle plate and Dr. Stephen Thorpe for his help with the mechanical testing. This work was supported by the ERC Starting Grant (STROFUNSCAFF), the FP7PEOPLE-2013-CIG Biomorph, the Royal Society and the European Space Agency (Drop My Thesis program, 2016).

Received: ((will be filled in by the editorial staff))

Revised: ((will be filled in by the editorial staff)) Published online: ((will be filled in by the editorial staff))

\section{References}

[1] C. Frantz, K. M. Stewart, V. M. Weaver, J. Cell Sci. 2010, 123, 4195.

[2] R. O. Hynes, Science 2009, 326, 1216.

[3] X. Hu, P. Cebe, A. S. Weiss, F. Omenetto, D. L. Kaplan, Mater. Today 2012, 15, 208.

[4] J. Malda, J. Visser, F. P. Melchels, T. Jüngst, W. E. Hennink, W. J. A. Dhert, J. Groll, D. W. Hutmacher, Adv. Mater. 2013, 25, 5011.

[5] H. Gudupati, M. Dey, I. Ozbolat, H. Gudapati, M. Dey, I. Ozbolat, Biomaterials 2016, 102, 20.

[6] K. Hölzl, S. Lin, L. Tytgat, S. Van Vlierberghe, L. Gu, A. Ovsianikov, Biofabrication 2016, 8,32002 
[7] F. Taraballi, S. Wang, J. Li, F. Y. Y. Lee, S. S. Venkatraman, W. R. Birch, S. H. Teoh, F. Y. C. Boey, K. W. Ng, Adv. Healthc. Mater. 2012, 1, 513.

[8] S. V Murphy, A. Atala, Nat. Biotechnol. 2014, 32, 773.

[9] F. Pati, J. Jang, D.-H. Ha, S. Won Kim, J.-W. Rhie, J.-H. Shim, D.-H. Kim, D.-W. Cho, Nat. Commun. 2014, 5, 3935.

[10] V. Mironov, R. P. Visconti, V. Kasyanov, G. Forgacs, C. J. Drake, R. R. Markwald, Biomaterials 2009, 30, 2164.

[11] M. Costantini, J. Idaszek, K. Szöke, J. Jaroszewicz, M. Dentini, A. Barbetta, J. E. Brinchmann, W. Święszkowski, Biofabrication 2016, 8, 35002.

[12] D. B. Kolesky, K. A. Homan, M. A. Skylar-Scott, J. A. Lewis, Proc. Natl. Acad. Sci. 2016, 201521342.

[13] M. Lovett, K. Lee, A. Edwards, D. L. Kaplan, Tissue Eng. Part B. Rev. 2009, 15, 353.

[14] M. P. Lutolf, J. a Hubbell, Nat. Biotechnol. 2005, 23, 47.

[15] M. J. Dalby, N. Gadegaard, R. Tare, A. Andar, M. O. Riehle, P. Herzyk, C. D. W. Wilkinson, R. O. C. Oreffo, Nat. Mater. 2007, 6, 997.

[16] S. Badylak, Nature 2016, 540, S55.

[17] J. Kisiday, M. Jin, B. Kurz, H. Hung, C. Semino, S. Zhang, a J. Grodzinsky, Proc. Natl. Acad. Sci. 2002, 99, 9996.

[18] J. D. Hartgerink, E. Beniash, S. I. Stupp, Science 2001, 294, 1684.

[19] A. C. Mendes, K. H. Smith, E. Tejeda-Montes, E. Engel, R. L. Reis, H. S. Azevedo, A. Mata, Adv. Funct. Mater. 2013, 23, 430.

[20] E. T. Pashuck, H. Cui, S. I. Stupp, J. Am. Chem. Soc. 2010, 132, 6041.

[21] S. Ribeiro, E. Radvar, Y. Shi, J. Borges, R. P. Pirraco, I. B. Leonor, J. Mano, R. L. L. Reis, A. Mata, H. S. Azevedo, Nanoscale 2017, 13670.

[22] A. Mata, Y. Geng, K. J. Henrikson, C. Aparicio, S. R. Stock, R. L. Satcher, S. I. Stupp, Biomaterials 2010, 31, 6004. 
[23] K. Rajangam, M. S. Arnold, M. A. Rocco, S. I. Stupp, Biomaterials 2008, 29, 3298.

[24] R. M. Capito, H. S. Azevedo, Y. S. Velichko, A. Mata, S. I. Stupp, Science 2008, 319, 1812.

[25] K. E. Inostroza-Brito, E. Collin, O. Siton-Mendelson, K. H. Smith, A. Monge-Marcet, D. S. Ferreira, R. P. Rodríguez, M. Alonso, J. C. Rodríguez-Cabello, R. L. Reis, F. Sagués, L. Botto, R. Bitton, H. S. Azevedo, A. Mata, Nat. Chem. 2015, 7, 897.

[26] A. C. Mendes, E. T. Baran, R. L. Reis, H. S. Azevedo, Wiley Interdiscip. Rev. Nanomedicine Nanobiotechnology 2013, 5, 582.

[27] J. Boekhoven, S. I. Stupp, Adv. Mater. 2014, 26, 1642.

[28] D. W. Urry, Prog. Biophys. molec. Biol. 1992, 57, 23.

[29] S. Zhang, M. a Greenfield, A. Mata, L. C. Palmer, R. Bitton, J. R. Mantei, C. Aparicio, M. O. de la Cruz, S. I. Stupp, Nat. Mater. 2010, 9, 594.

[30] S. Wang, Z. Wang, S. E. M. Foo, N. S. Tan, Y. Yuan, W. Lin, Z. Zhang, K. W. Ng, ACS Appl. Mater. Interfaces 2015, 7, 5187.

[31] G. D. Mogoşanu, A. M. A. Grumezescu, M. M. C. Chifiriuc, G. Mogosanu, A. M. A. Grumezescu, M. M. C. Chifiriuc, Curr. Drug Targets 2014, 15, 518.

[32] J. G. Rouse, M. E. Van Dyke, Materials 2010, 3, 999.

[33] P. Hartrianti, L. T. H. Nguyen, J. Johanes, S. M. Chou, P. Zhu, N. S. Tan, M. B. Y. Tang, K. W. Ng, J. Tissue Eng. Regen. Med. 2016, 4, 524.

[34] J. K. J. K. Placone, J. Navarro, G. W. G. W. Laslo, M. J. M. J. Lerman, A. R. A. R. Gabard, G. J. G. J. Herendeen, E. E. E. E. Falco, S. Tomblyn, L. Burnett, J. P. J. P. Fisher, Ann. Biomed. Eng. 2016, 45, 237.

[35] E. Antunes, C. F. Cruz, N. G. Azoia, A. Cavaco-Paulo, Int. J. Biol. Macromol. 2016, 89, 477.

[36] C. T. Buckley, S. D. Thorpe, F. J. O’Brien, A. J. Robinson, D. J. Kelly, J. Mech. Behav. Biomed. Mater. 2009, 2, 512.

[37] B. Raphael, T. Khalil, V. L. Workman, A. Smith, C. P. Brown, C. Streuli, A. Saiani, M. Domingos, Mater. Lett. 2017, 190, 103. 
[38] D. Seliktar, Science 2012, 336, 1124.

[39] A. Faulkner-Jones, C. Fyfe, D.-J. Cornelissen, J. Gardner, J. King, A. Courtney, W. Shu, Biofabrication 2015, 7, 44102.

[40] J. R. Castrejón-Pita, B. N. Muñoz-Sánchez, I. M. Hutchings, A. A. Castrejón-Pita, J. Fluid Mech. 2016, 809, 716.

[41] D. An, A. Warning, K. G. Yancey, C.-T. Chang, V. R. Kern, A. K. Datta, P. H. Steen, D. Luo, M. Ma, Nat. Commun. 2016, 7, 12401.

[42] V. Sharma, M. Szymusiak, H. Shen, L. C. Nitsche, Y. Liu, Langmuir 2012, 28, 729.

[43] S. Ungphaiboon, D. Attia, G. Gomez d'Ayala, P. Sansongsak, F. Cellesi, N. Tirelli, Soft Matter 2010, 6, 4070.

[44] J. S. Lee, S. J. Park, J. H. Lee, B. M. Weon, K. Fezzaa, J. H. Je, Nat. Commun. 2015, 6, 8187.

[45] A. A. C. Pita, J. R. C. Pita, I. M. Hutchings, Phys. Rev. E 2012, 86, 045301+.

[46] M. Szymusiak, V. Sharma, L. C. Nitsche, Y. Liu, Soft Matter 2012, 8, 7556.

[47] A. E. Jakus, A. L. Rutz, R. N. Shah, Biomed. Mater. 2016, 11, 14102.

[48] G. D. Prestwich, K. E. Healy, Expert Opin. Biol. Ther. 2015, 15, 3.

[49] L. R. Hart, J. L. Harries, B. W. Greenland, H. M. Colquhoun, W. Hayes, ACS Appl. Mater. Interfaces 2015, 7, 8906.

[50] Y. Loo, C. A. E. Hauser, Biomed. Mater. 2016, 11, 14103.

[51] A. Mata, L. Hsu, R. Capito, C. Aparicio, K. Henrikson, S. I. Stupp, Soft Matter 2009, 5, 1228.

[52] S. Wang, F. Taraballi, L. P. Tan, K. W. Ng, Cell Tissue Res. 2012, 347, 795.

[53] S. D. Hoath, W.-K. Hsiao, G. D. Martin, S. Jung, S. A. Butler, N. F. Morrison, O. G. Harlen, L. S. Yang, C. D. Bain, I. M. Hutchings, J. Nonnewton. Fluid Mech. 2015, 223, 28. 


\section{Table of Contents}

Bridging the gap between advanced biomaterials and biofabrication. A novel bioink whereby peptide amphiphiles (PAs) are used as "chaperones" to organize ECM proteins and biomolecules into hierarchical structures. The method takes advantage of interfacial forces generated between solutions of the co-assembling molecules enabling the possibility to bioprint while controlling biomolecular and structural elements of the printed scaffold.

Keywords: bioprinting, droplet-on-demand, bioink, self-assembly, peptide amphiphiles

Clara L. Hedegaard, Estelle C. Collin, Carlos Redondo-Gomez, Luong T. H. Nguyen, Kee Woei Ng, Alfonso A. Castrejón-Pita, J. Rafael Castrejón-Pita and Alvaro Mata*

\section{Hydrodynamically Guided Hierarchical Self-assembly of Peptide-Protein Bioinks}

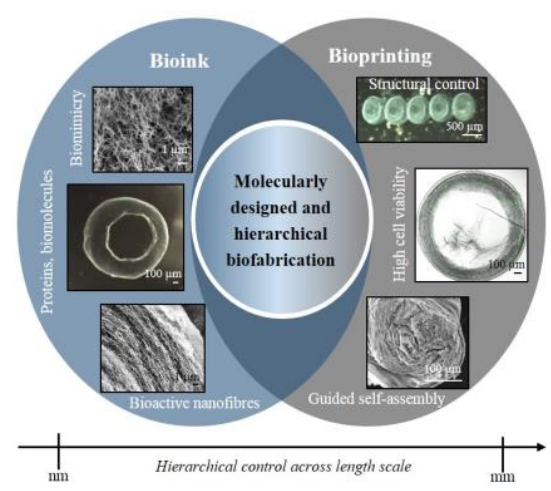




\section{Supporting Information}

\section{Hydrodynamically Guided Hierarchical Self-assembly of Peptide-Protein Bioinks}

Clara L. Hedegaard, Estelle C. Collin, Carlos Redondo-Gomez, Luong T. H. Nguyen, Kee Woei Ng, Alfonso A. Castrejón-Pita, J. Rafael Castrejón-Pita and Alvaro Mata*

\section{Supporting information contents:}

Section 1: Composition of keratin

Section 2: Peptide purification

Section 3: Material characterization - circular dichroism

Section 4: Co-assembly of PA and keratin

Section 5: Mechanical data

Section 6: Hydrogel stability in media

Section 7: Liquid content of PA/keratin gels

Section 8: Gel size

Section 9: Droplet velocity and size

Section 10: Droplet oscillations used to determine the viscosity

Section 11: Print-head precision

Section 12: Cell viability study 


\section{Section 1: Composition of keratin}

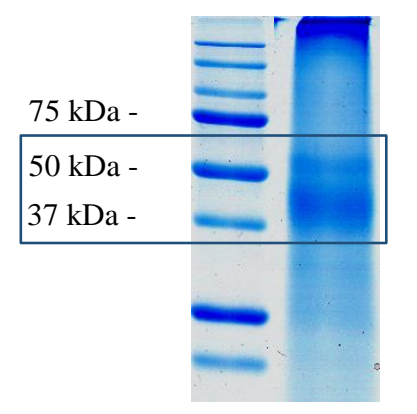

Figure S1. SDS-Page of keratin

Sodium Dodecyl Sulfate Polyacrylamide Gel Electrophoresis (SDS-PAGE) was carried out to determine the fraction of type I acidic (39-45 kDa) and type II basic $(50-55 \mathrm{kDa})$ keratin filaments in the extracted keratin originating from human hair. The SDS-PAGE was done using a $2 \mathrm{mg} \mathrm{ml}^{-1}$ keratin solution (in (10 mM HEPES $+0.9 \% \mathrm{NaCl}, \mathrm{pH} 7.5) .15 \mu \mathrm{l}$ of the sample solution was mixed with $5 \mu 15 \mathrm{x}$ sample buffer. The keratin solution was denatured at $75{ }^{\circ} \mathrm{C}$ for $10 \mathrm{~min}$. Sample buffer was made up of $0.25 \mathrm{~g}$ SDS (Bio-Rad 161-0301) dissolved in $0.625 \mathrm{ml} 1.25 \mathrm{M}$ Tris- $\mathrm{HCl}$ buffer, $\mathrm{pH}$ 6.8. The denatured samples were loaded into a precast $4 \%$ stacking gel and a $12 \%$ separating BisTris gel. A constant voltage $(50 \mathrm{~V})$ was applied until the samples reached the end of the stacking gel. Following this the electrophoresis was carried out at $120 \mathrm{~V}$. The separation gel was subsequently stained using Coomassie Blue (Invitrogen). The SDS-page yielded a thick band at 37$45 \mathrm{kDa}$, in line with the Type I acidic keratin filament, and a smaller band at 50-55 kDa, in line with the type II basic keratin filament (Figure S1).

\section{Section S2: Peptide preparation and purification}

\section{Solid-phase peptide synthesis (SPPS)}

Amino acid couplings were performed using 4 equivalents $(4 \mathrm{mmol})$ of Fmoc-protected amino acids (Novabiochem Corporation, USA), 4 equivalents of 1-hydroxybenzotriazol (HOBT, Carbosynth Limited, UK) and 6 equivalents of N,N'-diisopropylcarbodiimide (DIC, Sigma-Aldrich, UK). Fmoc deprotections were performed with $20 \%$ piperidine (Sigma-Aldrich, UK) in N,Ndimethylformamide (DMF). Following Fmoc removal from the final amino acid residue, the alkyl tail moiety (from palmitic acid, Sigma-Aldrich, UK) was conjugated to the free $\mathrm{N}$-terminus. The alkylation reaction was accomplished by using 4 equivalents of the palmitic acid, 4 equivalents of HOBT and 6 equivalents of DIC in DMF/dichloromethane 2:3. The reaction was allowed to proceed overnight until the Kaiser test was negative. Cleavage of the PA from the resin and deprotection were carried out with a mixture of trifluoracetic acid (TFA, Sigma-Aldrich, UK)/triisopropylsilane (TIS, Alfa Aesar, UK)/water (95:2.5:2.5) for $3 \mathrm{~h}$ at room temperature. After filtration of the cleavage mixture, the TFA was removed under vacuum and the resulting viscous peptide solution was precipitated with cold diethylether at $-20^{\circ} \mathrm{C}$, the white precipitate was collected by centrifugation, washed twice with cold diethylether, allowed to dry overnight, suspended in water and lastly freeze-dried.

\section{Purification}

Peptide purification was carried out using 2545 binary gradient preparative Reverse Phase HighPerformance Liquid Chromatography (RP-HPLC) (Waters, USA) with a 2489 UV/Visible detector (Waters, USA) using a C18 column (Atlantis Prep OBD T3 Column, Waters, USA) and a water/acetonitrile $(0.1 \%$ TFA) gradient. TFA counter-ions were exchanged by sublimation from $0.01 \mathrm{M}$ hydrochloric acid. Finally, the peptides were dialyzed against deionized water using 500 
MWCO dialysis tubing (Spectrum Europe B.V., The Netherlands) to remove salts, lyophilized to obtain a fluffy powder, and stored in closed containers at $-20{ }^{\circ} \mathrm{C}$ until use. The mass of the peptides was confirmed by electrospray ionization (ESI, Agilent LC-MS, comprising an 1100 Series LC and SL Ion Trap MSD, Agilent, USA). For each peptide sequence used, the ESI-MS spectrum and the RP-HPLC traces are shown below:

2.1) $\mathrm{C}_{15} \mathrm{H}_{31} \mathrm{CONH}-\mathrm{V}_{3} \mathrm{~A}_{3} \mathrm{VPGIGK} \mathrm{K}_{3}$
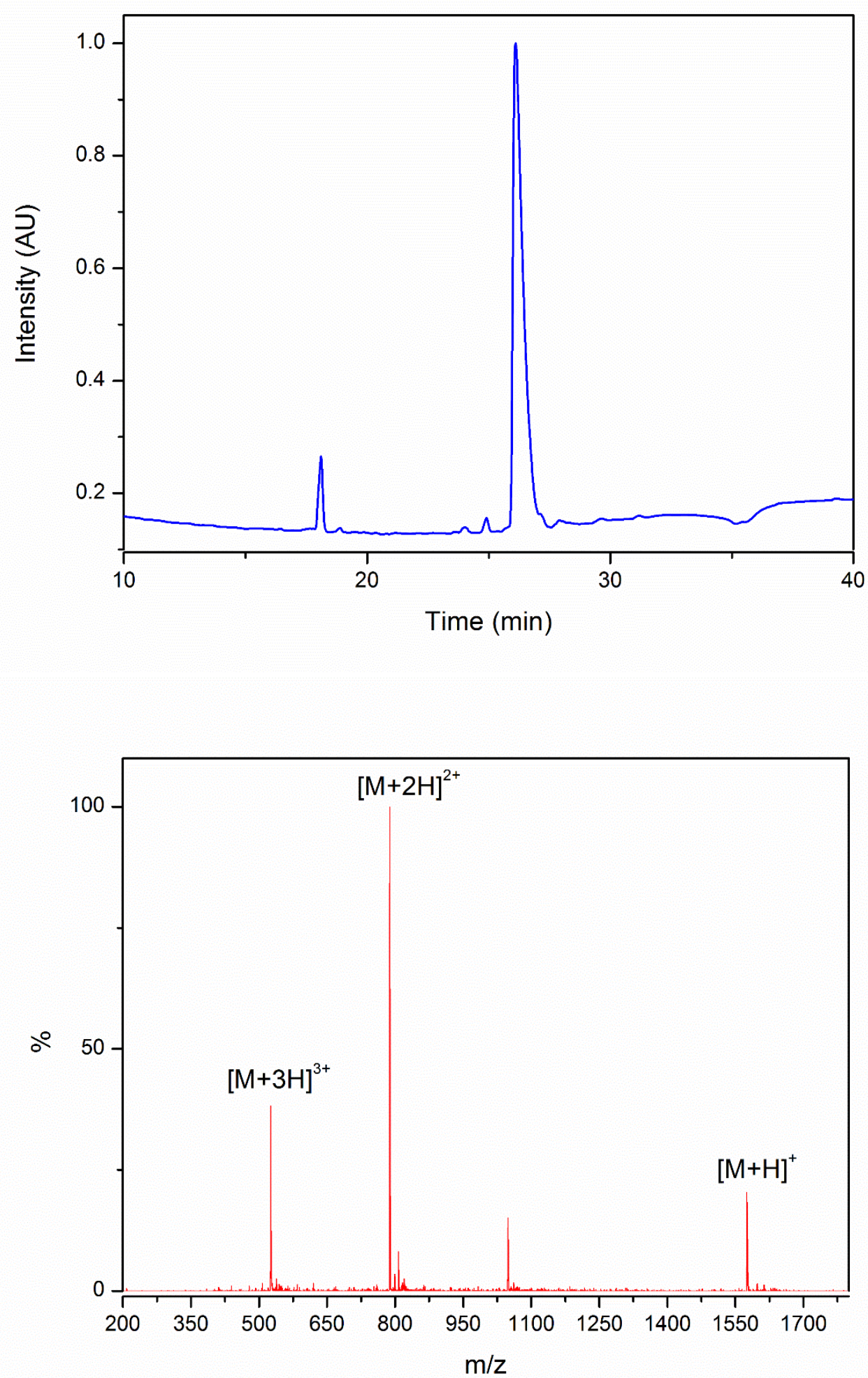

Figure S2.1. ESI-MS spectrum and the RP-HPLC trace of $\mathrm{PA}_{1}$ 
2.2) $\mathrm{C}_{15} \mathrm{H}_{31} \mathrm{CONH}-\mathrm{V}_{3} \mathrm{~A}_{3} \mathrm{H}_{2} \mathrm{~K}$
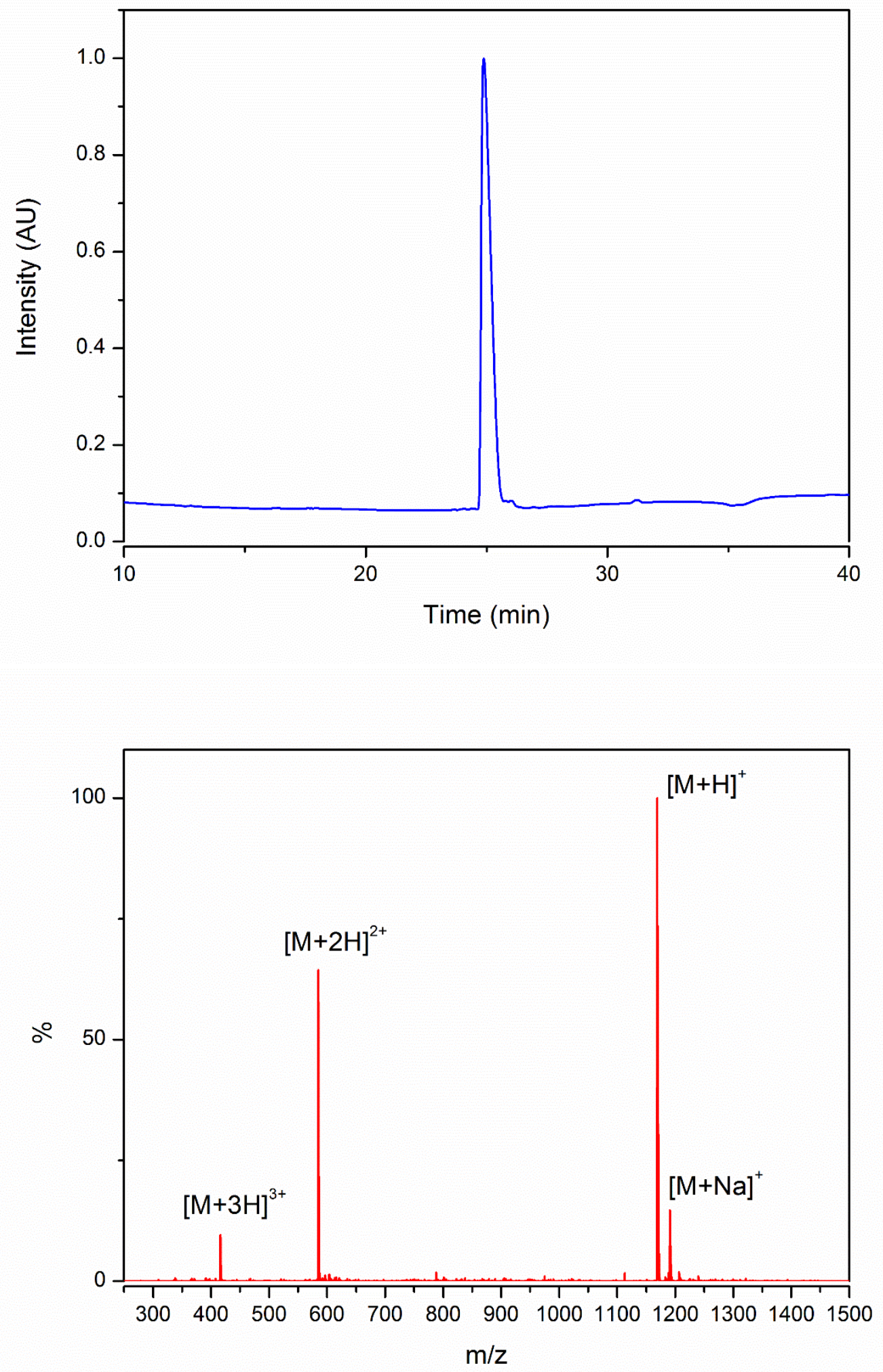

Figure S2.2. ESI-MS spectrum and the RP-HPLC trace of $\mathrm{PA}_{2}$ 
2.3) $\mathrm{C}_{15} \mathrm{H}_{31} \mathrm{CONH}-\mathrm{V}_{3} \mathrm{~A}_{3} \mathrm{~K}_{3}$
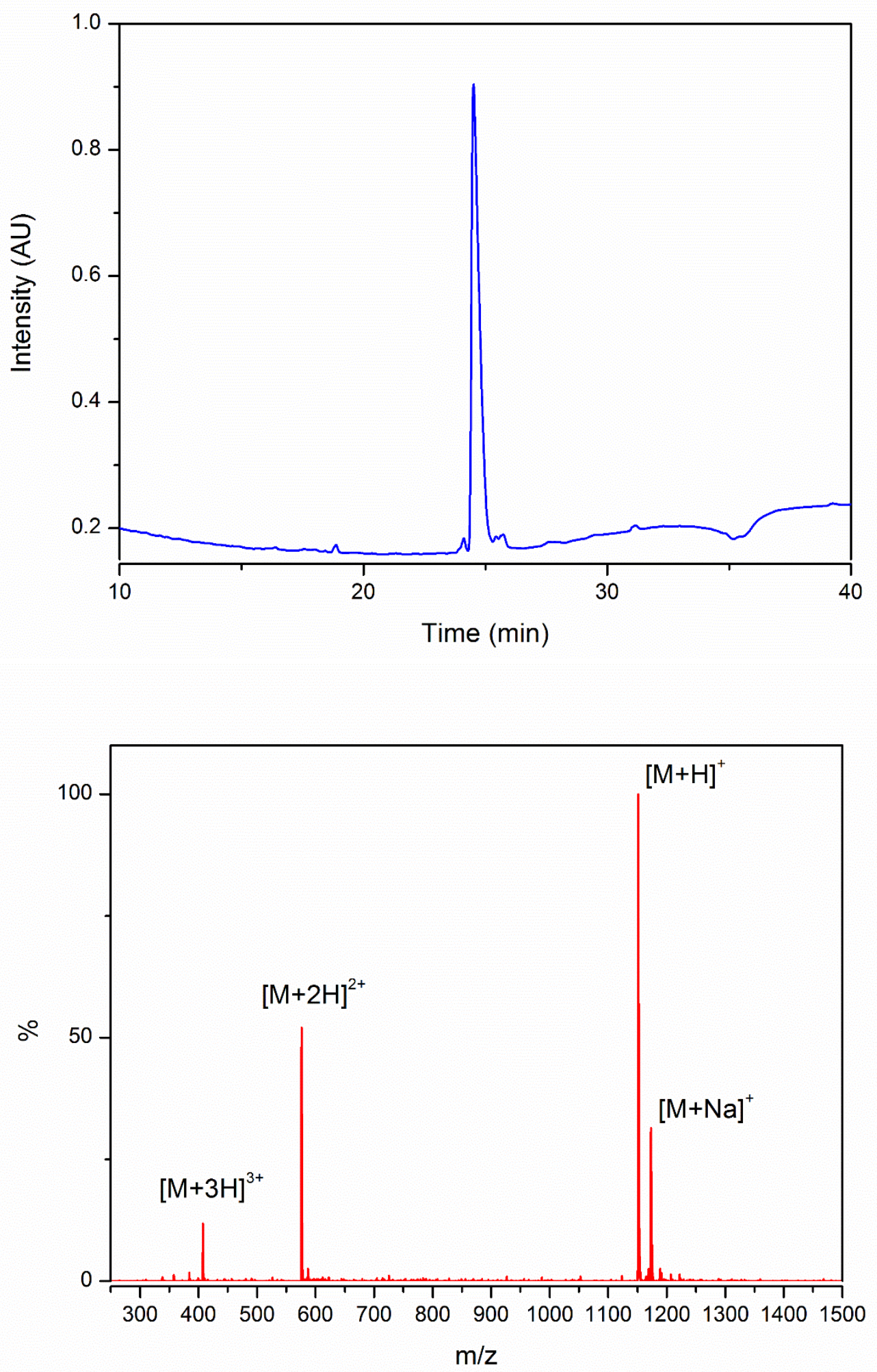

Figure S2.3. ESI-MS spectrum and the RP-HPLC trace of $\mathrm{PA}_{3}$ 

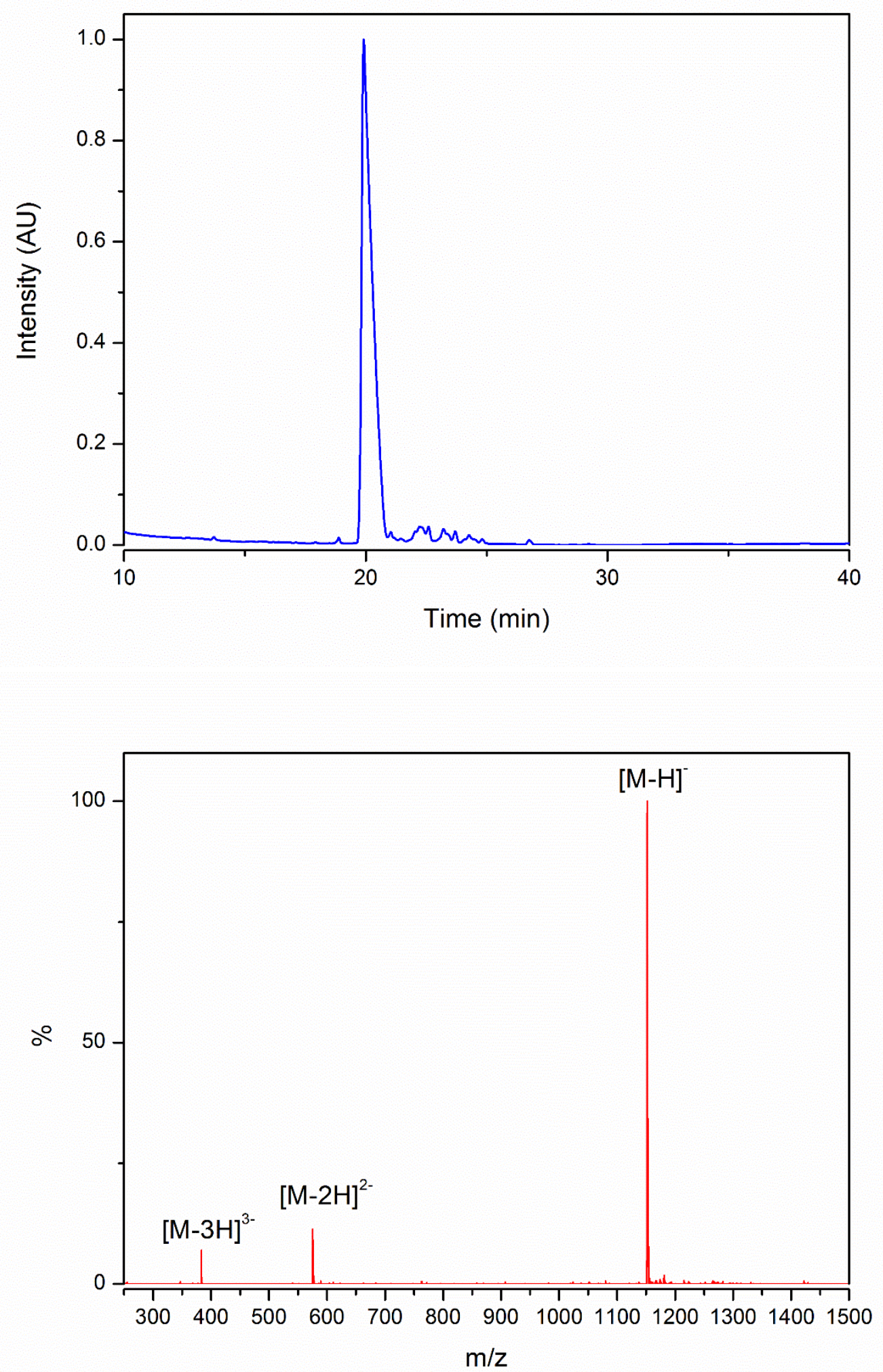

Figure S2.4. ESI-MS spectrum of $\mathrm{PA}_{4}$ 


\section{Section 3: Material characterization - circular dichroism of $\mathbf{P A}_{1}, \mathbf{P A _ { 2 }}$ and keratin}

Circular dichroism (CD) of $\mathrm{PA}_{1}, \mathrm{PA}_{2}$ and keratin, carried out at a constant molar concentration of $20 \mu \mathrm{M}$. Solutions were prepared using HEPES buffer (10 mM HEPES + 0.9\% NaCl, pH 7.5). Both PAs exhibited $\beta$-sheet signal, whereas keratin exhibited an $\alpha$-helix conformation. At equal molar concentration, there is an excess of keratin in the mixture of PA/keratin, due to the difference in molecular weight, which is reflected in the CD-signal.

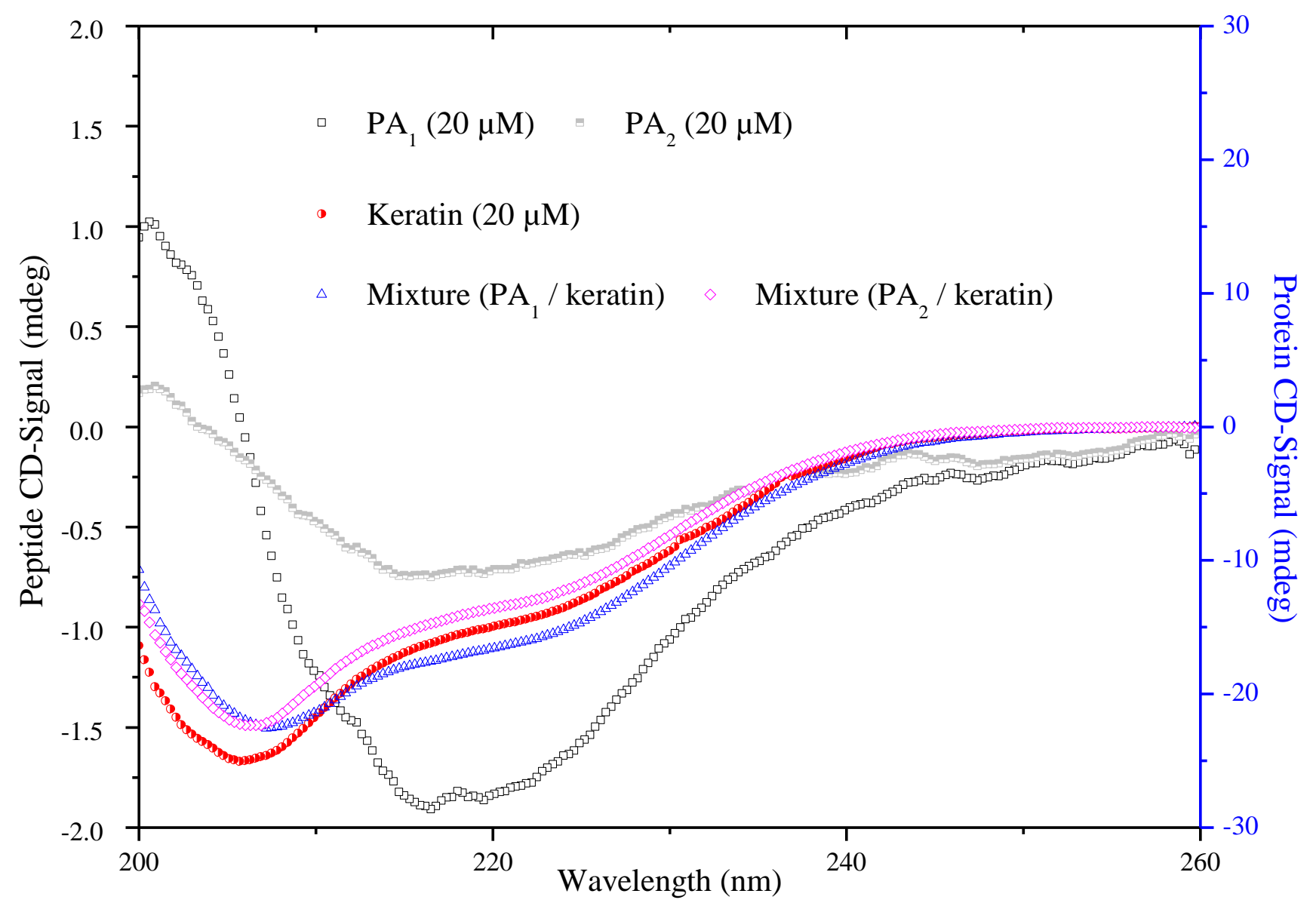

Figure S3. CD spectra of $\mathrm{PA}_{1} \& \mathrm{PA}_{2}$, keratin and the $1: 1(\mathrm{v} / \mathrm{v})$ mixture at equal molar concentration 


\section{Section 4: Co-assembly of PA and keratin}

4.1 Direction of diffusion - PA/keratin
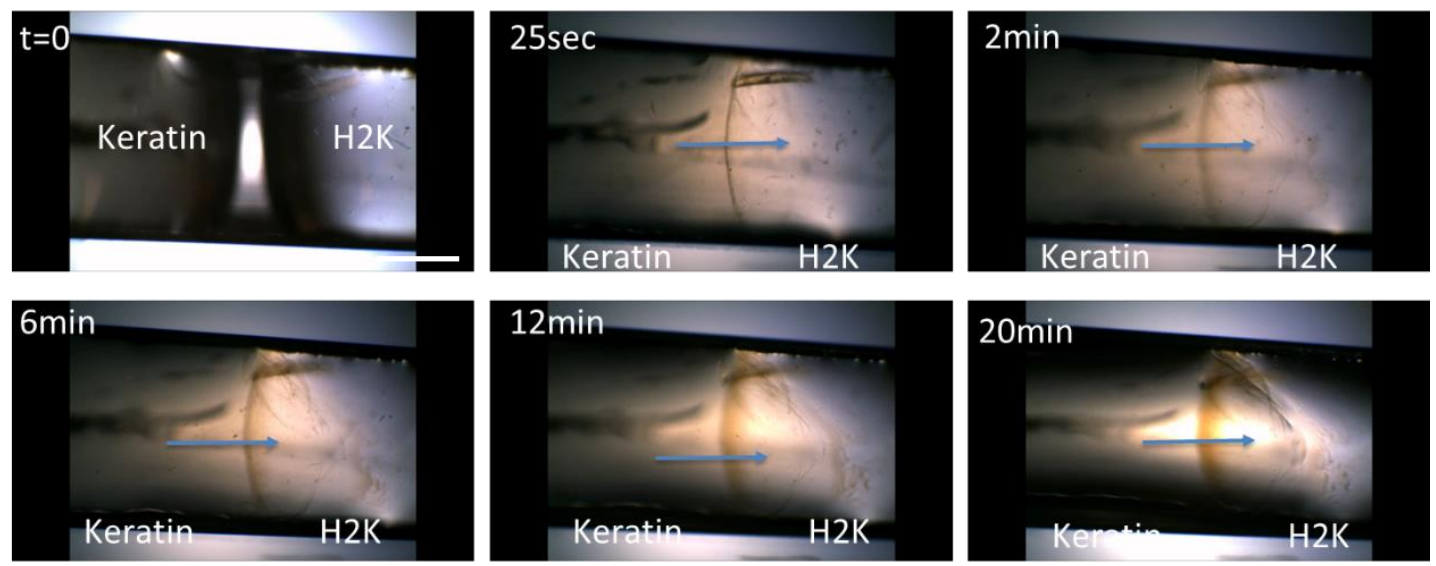

Figure S4. Time lapse of keratin being brought in contact with $\mathrm{PA}_{2}$ (scale bar $1 \mathrm{~mm}$ )

A solution of $\mathrm{PA}_{2}\left(10 \mathrm{mg} \mathrm{ml}^{-1}\right.$, HEPES buffer) was brought in contact with a solution of keratin (10 $\mathrm{mg} \mathrm{ml}^{-1}$, HEPES buffer). Both solutions were placed in a soft half-cylindrical PDMS mold, leaving a small distance at the interface, which is eventually overcome by capillary forces. Upon contact a membrane is formed at the interface, followed by further gelling on the PA side. The gelation on the PA side indicates that keratin is diffusing towards PA.

4.2 Co-assembly duration - PA/keratin
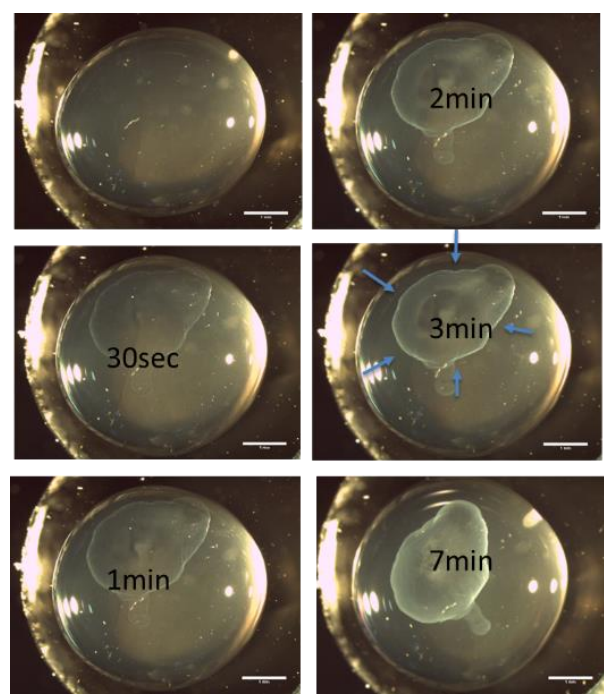

Figure $\mathbf{S 5} .20 \mu \mathrm{l}$ of keratin with $5 \mu \mathrm{l}$ of $\mathrm{PA}_{2}$ injected at $\mathrm{t}=0$ (scale bar $1 \mathrm{~mm}$ )

A similar study to Figure S4 was carried out using a Leica MZ12 ${ }_{5}$ Microscope. Here $5 \mu 1$ of PA $2(10$ $\mathrm{mg} \mathrm{ml}^{-1}$, HEPES buffer) was injected into the middle of a blob of $20 \mu 1$ keratin solution $\left(10 \mathrm{mg} \mathrm{ml}^{-}\right.$

1 , HEPES buffer). The time lapse series shows increasing definition of the hydrogel over the course of the first $7 \mathrm{~min}$. A similar trend was observed by leaving the gels for $24 \mathrm{~h}$. 


\section{Section 5: Mechanical data}

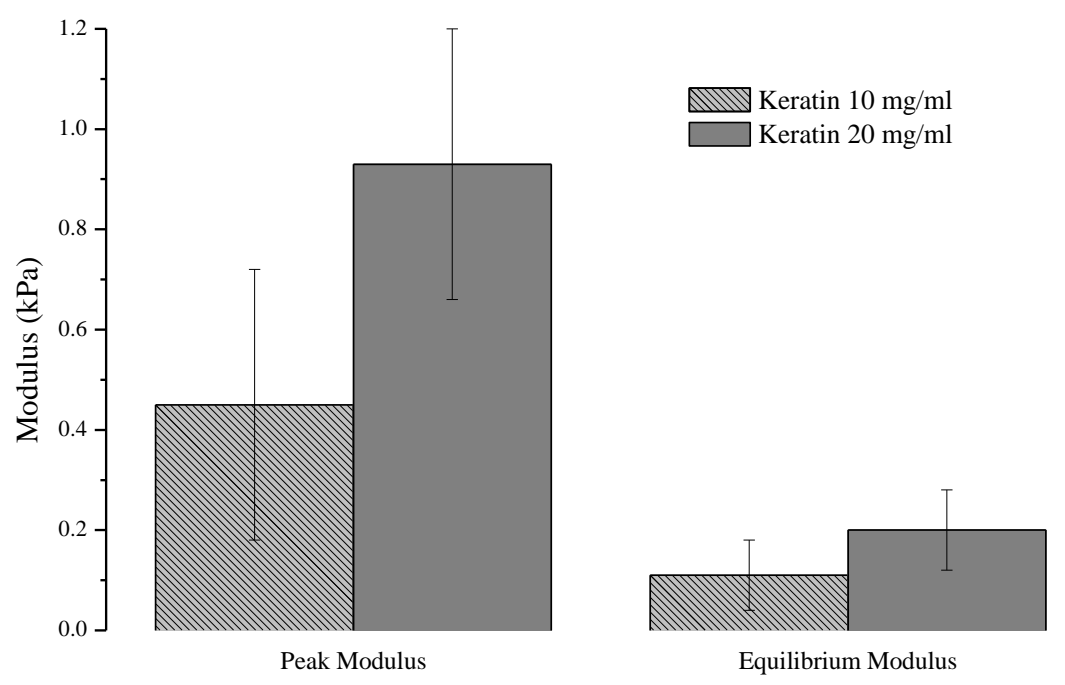

Figure S6. Peak and equilibrium modulus (@ 20\% strain) of $\mathrm{PA}_{2}$-keratin hydrogels (Average reported with \pm standard deviation, $\mathrm{n}=5$ for all conditions)

\section{Section 6: Hydrogel stability in media}

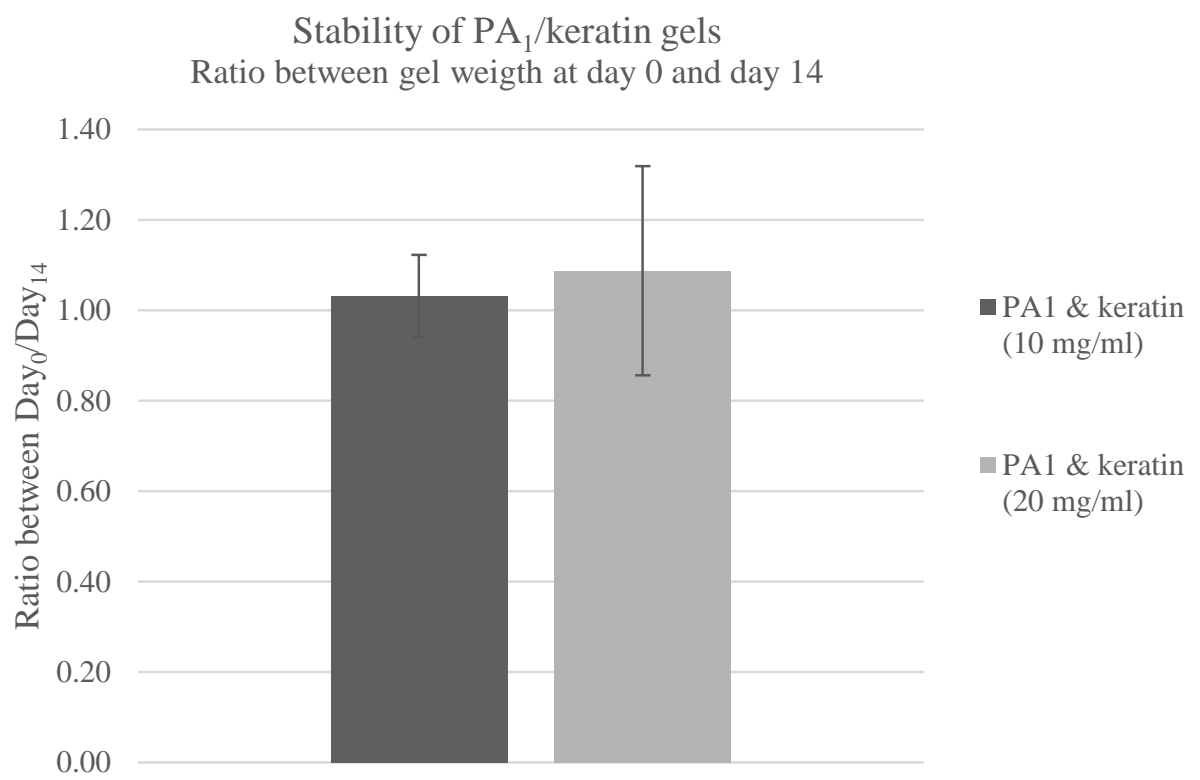

Figure S7. Hydrogel stability in media and incubation $\left(37^{\circ} \mathrm{C}\right)$, PA1 data presented.

PA/keratin gels were prepared using $\mathrm{PA}_{1}$ and $\mathrm{PA}_{2}\left(10 \mathrm{mg} \mathrm{ml}^{-1}\right.$ in HEPES $)$ and keratin at $10 \mathrm{mg} \mathrm{ml}^{-1}$ $(\mathrm{n}=3)$ and $20 \mathrm{mg} \mathrm{ml}^{-1}(\mathrm{n}=3)$. Gels were left to form for $24 \mathrm{~h}$. Samples were weighed prior to incubation. The samples were subsequently placed in $200 \mu 1$ media for 14 days at $37^{\circ} \mathrm{C}$. Following the incubation period the samples were re-weighed and visually compared to images of the gels at day 0. No significant visual difference was observed. The difference in weight (Figure S7) indicates a negligible change, and therefore the gels were concluded to be stable in media. (Sample number, $\mathrm{n}$ $\geq 3$ ) 


\section{Section 7: Liquid content of PA/keratin gels}

$\mathrm{PA} /$ keratin gels were prepared using $\mathrm{PA}_{2}\left(10 \mathrm{mg} \mathrm{ml}^{-1}\right)$ and keratin $\left(20 \mathrm{mg} \mathrm{ml}^{-1}\right)$. Gels were left to form for $24 \mathrm{~h}$. All samples ( $\mathrm{n}=9$ ) were weighed to determine the hydrated weight and subsequently freeze dried. Following the freeze drying process the gels were weighed again, to obtain the dehydrated weight. The values were normalized to evaluate the water content in samples. A liquid content of $95 \pm 2 \%$ was determined.

Solid/liquid distribution of hydrogel

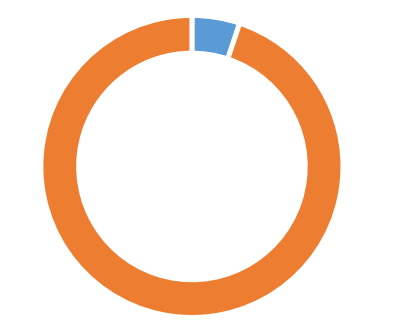

- Solid fraction $\quad$ Liquid fraction

Figure S8. Liquid content of $\mathrm{PA}_{2} /$ keratin gel 


\section{Section 8. Gel size}

Whilst the study has been done using a relatively large nozzle head (500 $\mu \mathrm{m}$ diameter), the experiments can be performed using down to at least a $100 \mu \mathrm{m}$ nozzle diameter. In this case it is possible to produce droplets with a diameter of $169 \pm 6 \mu \mathrm{m}$. This results in hydrogels of $168 \pm 15$ $\mu \mathrm{m}$, highlighting high the resolution achievable with the system. Figure S9 shows toroidal hydrogels made with a $100 \mu \mathrm{m}$ diameter nozzle.
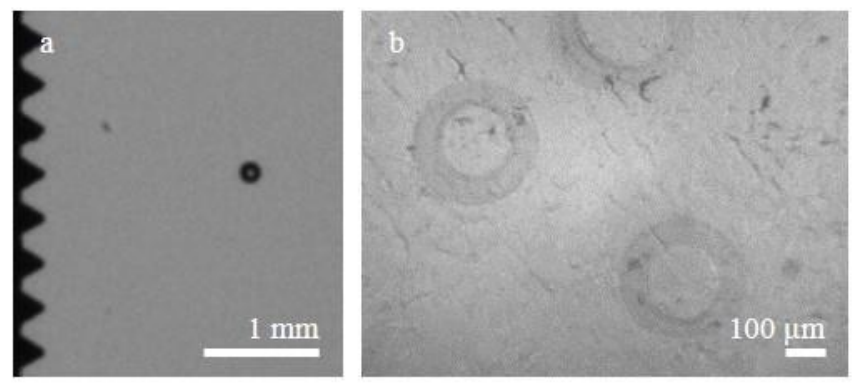

Figure S9. Example of (a) a droplet of PA jetted from a $100 \mu \mathrm{m}$ nozzle diameter and (b) the resulting micro hydrogels when jetting PA into keratin. 


\section{Section 9. Droplet velocity and size}

Using a high-speed camera (Phantom V170), droplets jetted from the print-head were filmed. All videos were analyzed using a Matlab image analysis tool, to obtain droplet radius and speed. To obtain the droplet speed, the center of mass of the droplet was plotted against time (given from the Matlab code), as seen in Figure S10. We observed no change in speed as an effect of drag or gravitation. The range of amplitudes $(15-25 \mathrm{~V})$ and pulse duration (1-3ms), resulted in droplet speeds of 0.5-2.5 m s$~^{-1}$. Figure $\mathrm{S} 8$ shows an example of the plotted droplet diameters and speeds for keratin $\left(10 \mathrm{mg} \mathrm{ml}^{-1}\right)$ and $\mathrm{PA}_{2}\left(10 \mathrm{mg} \mathrm{ml}^{-1}\right)$ droplets. The analysis was carried out for all substances used in the study.
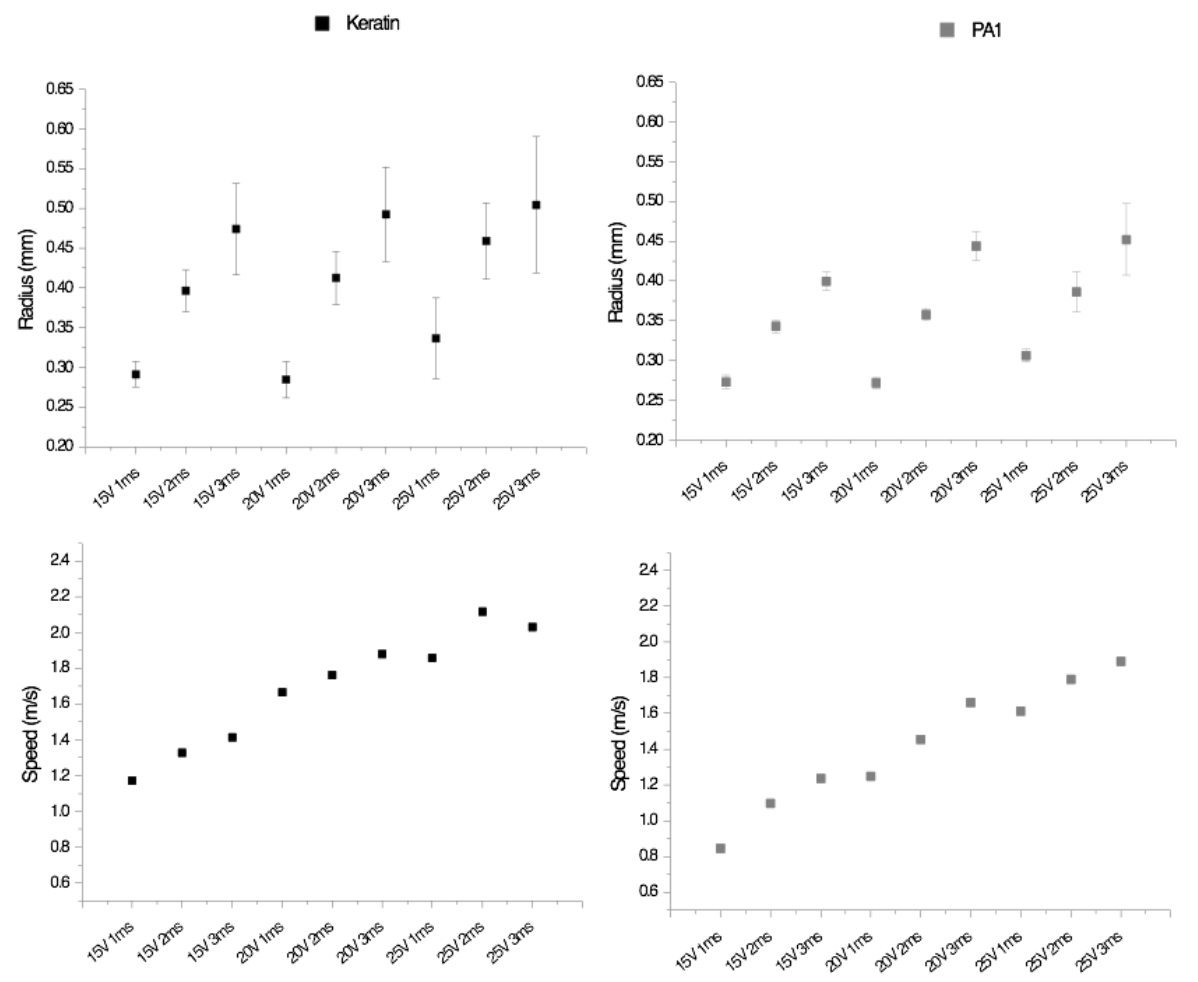

Figure S10. Droplet radius (mm) and Velocity $\left(\mathrm{m} \cdot \mathrm{s}^{-1}\right)$ for PA1 $\left(10 \mathrm{mg} \mathrm{ml}^{-1}\right)$ and keratin $\left(10 \mathrm{mg} \mathrm{ml}^{-1}\right)$

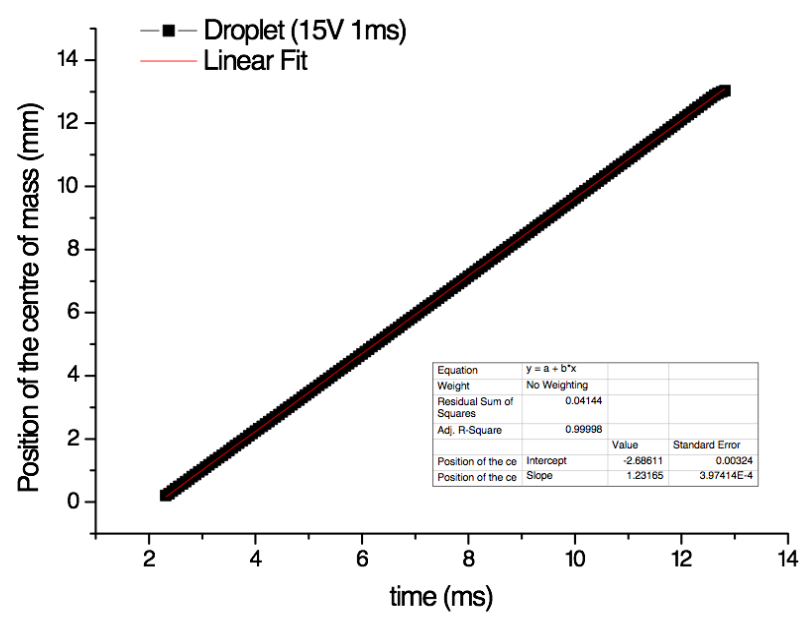

Figure S11. Example of droplet velocity. Keratin $\left(10 \mathrm{mg} \mathrm{ml}^{-1}\right)$ at pulse amplitude $15 \mathrm{~V}$ and duration $1 \mathrm{~ms}$ 


\section{Section 10: Droplet oscillations used to determine the viscosity}

The viscosity $(\mu)$ of each solution was derived from analyzing the in-flight droplet radial oscillations following the method previously published by Hoath et al. in 2015. ${ }^{[1]}$ Figure S12 shows an example of the oscillation behavior for a keratin droplet (Pulse amplitude $20 \mathrm{~V}$, width $1 \mathrm{~ms}$ ) from the print-head. According to this method, the fundamental radial oscillation of a droplet is given by

\section{Equation S1}

$$
r=r_{0}+A \exp \left(-\frac{t}{\tau}\right) \sin \left(\Omega\left(t-t_{0}\right)\right)
$$

where $\tau$ is the decay time, $\mathrm{r}_{0}$ average droplet radius, $\mathrm{t}_{0}$ a given phase, and $\Omega$ the angular frequency of the oscillation. Surface tension and viscosity are obtained by obtaining $\Omega$ and $\tau$, and using the following relationships:

\section{Equation S2}

$$
\tau=\frac{\rho r_{0}^{2}}{5 \mu}, \quad \text { and } \quad \Omega=\sqrt{\frac{8 \sigma}{\rho r_{0}^{3}}-\frac{1}{\tau^{2}}}
$$

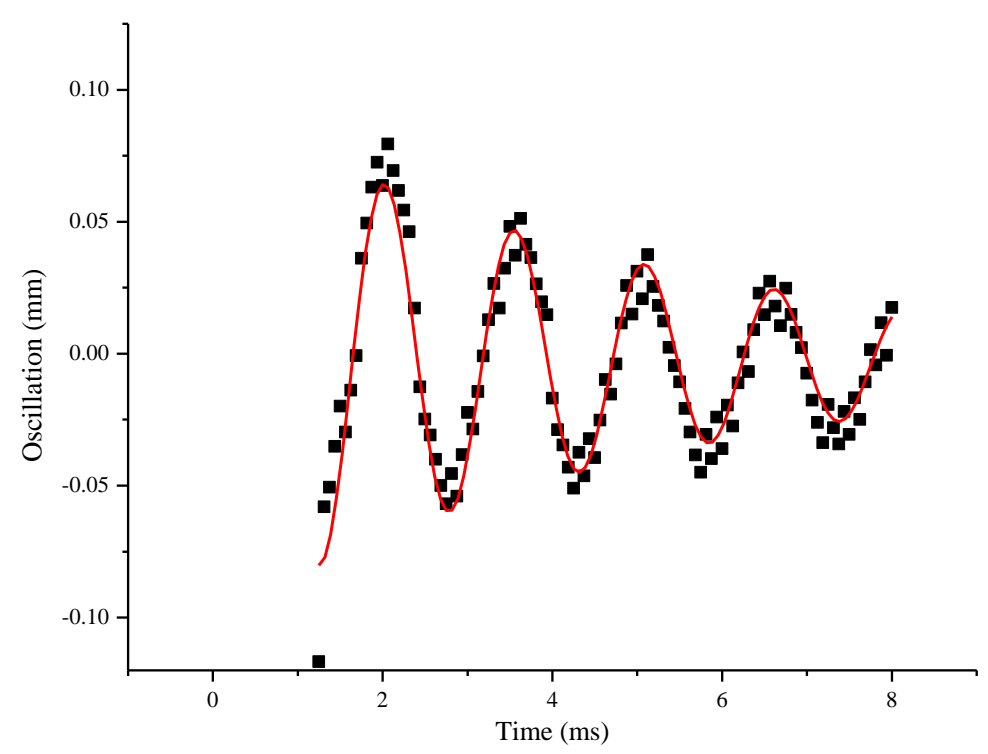

Figure S12. An example of fitting the oscillation curve to obtain viscosity and surface tension (Keratin $20 \mathrm{~V}, 1 \mathrm{~ms}$ ) 


\section{Section 11: Print-head precision}

The $\mathrm{x} / \mathrm{y}$-stage used to create $2 \mathrm{D}$-structures was first tested using water, to optimize droplet interval and speed of stage movement.
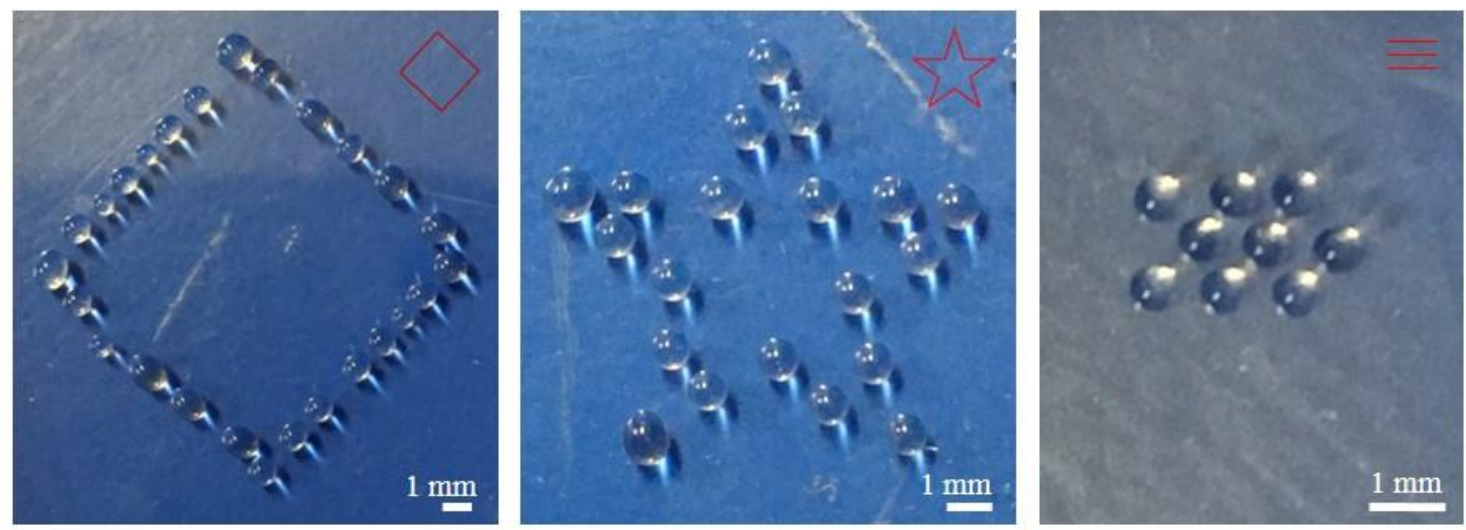

Figure S13. An example of the print-head precision, (a) left a square, (b) middle a star and (c) right an array for sheet formation, all done using water and a $500 \mu \mathrm{m}$ nozzle 


\section{Section 12: Cell viability study}

Cell viability of encapsulated cells in either the jetted solution or the bulk solution, was calculated based on a live/dead assay. Encapsulation of NIH-3T3 cells at $5 \mathrm{M}$ cells/ml in $\mathrm{PA}_{2}\left(10 \mathrm{mg} \mathrm{ml}^{-1}\right.$, HEPES buffer) was found to be $97 \pm 8 \%$ and in keratin $\left(10 \mathrm{mg} \mathrm{ml}^{-1}\right.$, HEPES buffer) was found to be $97 \pm 3 \%$. The controls were $97 \pm 3 \%$ and $90 \pm 12 \%$ respectively. Encapsulation of adipose derived stem cells (ADSCs) at $5 \mathrm{M}$ cells $/ \mathrm{ml}$ in $\mathrm{PA}_{2}\left(10 \mathrm{mg} \mathrm{ml}^{-1}\right.$, HEPES buffer) was found to be 62 $\pm 8 \%$ with the control $66 \pm 4 \%$, i.e. a comparative viability of $93 \%$.

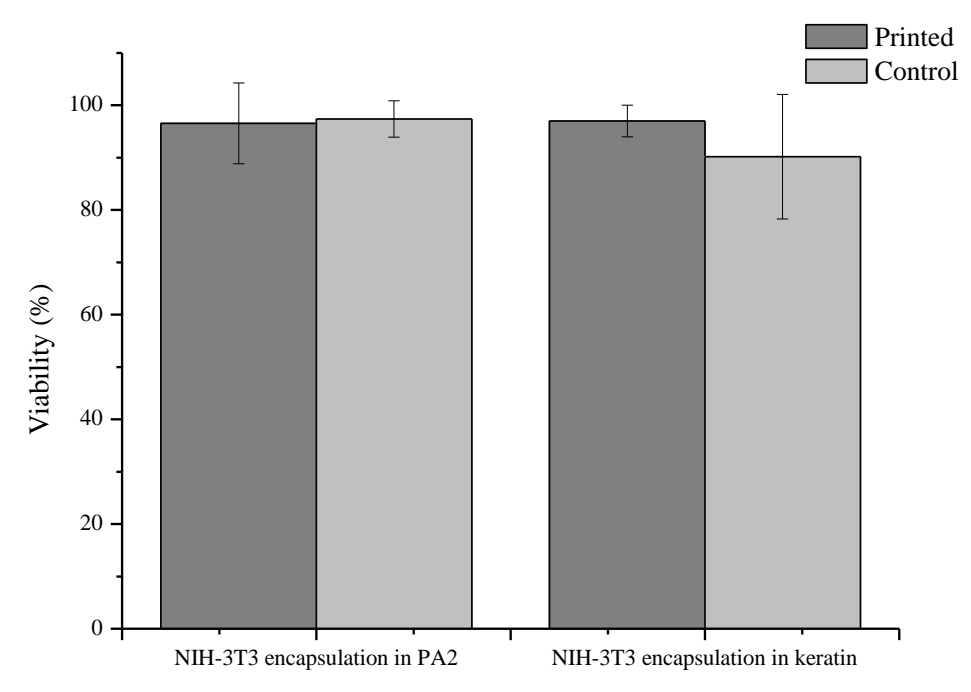

Figure S14. Cell viability of encapsulation studies performed using $\mathrm{PA}_{2}$

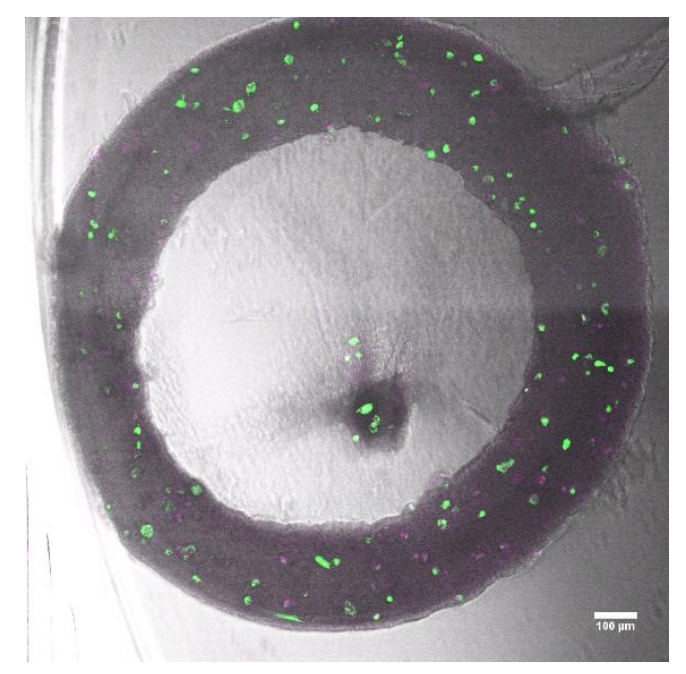

Figure S15. Cell viability of encapsulation of ADSCs in $\mathrm{PA}_{2}$ and printed (Live/dead assay pseudo colored green (live) and magenta (dead)) (scale bar $100 \mu \mathrm{m})$ 


\section{Supplementary references}

[1] S. D. Hoath, W.-K. Hsiao, G. D. Martin, S. Jung, S. A. Butler, N. F. Morrison, O. G. Harlen, L. S. Yang, C. D. Bain, I. M. Hutchings, J. Nonnewton. Fluid Mech. 2015, 223, 28. 